\title{
A System Dynamics Analysis of Value Creation in Project Context
}

\author{
Farzad Pargar $^{1 *}$ and Jaakko Kujala ${ }^{2}$
}

\begin{abstract}
The focus of this paper is on analyzing the value creation dynamics in the project implementation phase. By value creation, we mean the activities, processes, and strategies that the project team uses to increase benefits and/or reduce costs in the project. By synthesizing the literature on project management and system dynamics, we developed a simulation model with various structures underlying project dynamics. We considered four structures that influence project realized value: project team features, project characteristics, project controls and value creation processes, and project remedial actions due to ripple effects. The resulting model can systematically examine the interplay of value creation processes: work progression, rework, redesign and innovation, and rescheduling. We used the model to explain how the project team's capability, motivation, and speed of making the best-for-project decisions ensure that the value creation goals are met. We simulate various scenarios that show the significance of the processes and their influencing structures on the realized value. The results present how endogenous and exogenous drivers of system behavior unfold over time and provide a richer understanding of the effect of various model structures such as project complexity and uncertainty on value creation.
\end{abstract}

\section{Keywords}

Value creation, Simulation analysis, Project management, System dynamics, Rework, Redesign and innovation, Rescheduling

\footnotetext{
1*Utrecht University School of Economics, Utrecht University, Utrecht, the Netherlands, f.pargar@uu.nl (Corresponding Author)

${ }^{2}$ Industrial Engineering and Management, Faculty of Technology, University of Oulu, Oulu, Finland 


\section{Introduction}

There has in recent years been a shift within the project community from 'product creation' to 'value creation' by realising the benefits to justify the resources deployed in projects (MacDonald et al., 2012; Martinsuo et al., 2019; Winter and Szczepanek, 2008; Winter et al., 2006). Consequently, identification of the elements of value that the project aims to produce and their preservation defines the success or failure of a project (Lechler and Dvir, 2010). Several studies have shown that a project can still be a failure even if the product is delivered on time, on budget, and of the defined quality (eg, Samset, 2009; Shenhar and Dvir, 2007; Zwikael and Smyrk, 2012; Chih and Zwikael, 2015).

There has been a competing perspective of value creation in the literature for a wide range of stakeholders (Fuentes et al., 2019). Delivering value in projects can be approached from various dimensions of value such as economic, social, and environmental. It can also be approached from the timeframe of evaluation (Kivilä et al., 2017; MacDonald et al., 2012). In this paper, value is defined from the owner's perspective by focusing on its economic dimension and dividing the project product benefits which are quantified in monetary terms to the project costs (adapted from Laursen and Svejvig, 2016; Morris, 2013). A project team can deliver value by increasing the shortterm or long-term project product's benefits and/ or reducing project cost. For example, in tunnel construction, the project team can reduce the costs by using the (contaminated) soil from the tunnel and putting them back into the roadway/railway structure by obtaining the relevant permits on time and avoiding transferring the required soil from other sources. The project team can also increase the product benefits by discovering and implementing innovative solutions which improve product features, usability, and safety-related targets.

Much of the extant literature on project management emphasises on the importance of value maximisation and exploiting project opportunities to reduce cost or increase benefit (e.g., Alliance Executive Team, 2018; Hietajärvi et al., 2017a; Love et al., 2016). However, it is essential to understand how and through which project mechanisms the project team can deliver a valuable product. The paper aims to investigate the dynamics of four value creation processes and their influencing factors in a project's implementation phase to deliver more valuable outputs.

Conventional techniques such as earned value management follow a linear logic to reach the operational plans by just considering time and cost without addressing quality, uncertainty, risk, and opportunity (Browning, 2014). However, recent research shows that the project lives in a dynamic environment in which its goals, requirements, and implementation status evolving throughout the project's lifetime (Aritua et al., 2009; Lee et al., 2006). Therefore, the projects delivered in such a dynamic environment should not only predict the likely cost and schedule overruns but also involve remedial actions in response to changes to cope with uncertainties and increase the chance of holistic success (Locatelli et al., 2014). As projects involve non-linear interdependent components that may form multiple feedback mechanisms and dynamic complexity, it is difficult to understand how the value of a project is updated with uncertainty prevailing and propose proper remedial actions. Therefore, a system dynamics approach is suitable for their modelling to produce an explicit understanding of value creation processes. System dynamics is a suitable methodology to develop a process theory of how value is created over time in terms of the sequence of events, activities, and choices leading to a valuable project outcome (Pargar et al., 2019).

The system dynamics modelling can explicitly reveal feedback relationships among factors that might not be close in time and distance and clarify how value creation processes emerge, change, and unfold over time (Sterman, 2000). Various studies have applied system dynamics to understanding and improving project management principles (Lyneis and Ford, 2007; Lyneis et al., 2001; Sterman, 2000). Traditional system dynamics applications in project contexts focus on efficient project implementation by delivering the project as planned (Ford and Lyneis, 2013; Lyneis and Ford, 2007) and largely dismissed value-based outcomes.

Engineering Project Organization Journal

(C) 2018 Engineering Project Organization Society www.epossociety.org 
This paper contributes to current research by developing a system dynamics simulation model to analyse how can a project team produce a valuable outcome by responding to changes in the project implementation phase. We integrated the existing feedback loops and causal relationships in the literature (Ford and Sterman, 2003; Lyneis and Ford, 2007; Pargar et al., 2019) and quantified them into a simulation model to explore the effect of various model structures such as project team capabilities and project complexity and uncertainty on value creation. We presented the structures underlying project dynamics in four groups: project team features, project characteristics, project controls and value creation processes, and project remedial actions due to ripple effects. These structure are not case specific and are considered commonly for wide variety of projects such as construction and digital projects. However, the project team features and project characteristics are project specific and varies among projects. We use the model to simulate various scenarios that show the significance of the identified processes and their influencing structures on the realised value. We present how endogenous and exogenous drivers of system behaviour unfold over time to provide a richer understanding of the effect of various model structures such as project characteristics and project team features on value creation.

The rest of this paper is organised as follows. Section 2 discusses the research method. Theoretical background and structures underlying project dynamics are explained in Section 3. Then, in Section 4 the system dynamics model is presented, including the main mechanisms of the model; Experiments are carried out under diverse situations in Section 5, including the impact of the identified structures and processes on value creation. Finally, Section 6 concludes the research with summary and remarks.

\section{Research Method}

In this paper, system dynamic simulation is selected as a method for the development of a theoretical model of how value is created in the project implementation phase. Simulation and modelling can be used as a tool for theory development in various studies to explicitly define complex relationships between theoretical constructs (Davis et al., 2007). Simulation analyses can help us to understand various interdependent processes that could results in nonlinear system behaviour (Harrison et al., 2007).

The development of the simulation model is based on our analysis of existing reports and literature on project management. We considered a hypothetical project to run the simulation experiments and well-established SD models in the literature were used as reference sources for formulating the relationships among variables. During the model development, we utilized the relevant equations and tested different input data to generate valid outcome based on the behavior of interest which is well aligned with previous findings (Alliance Executive Team, 2018; Ford and Sterman, 2003; Lyneis and Ford, 2007; Pargar et al., 2019).

System dynamics modelling and simulation are increasingly used to understanding and improving project management by taking an aggregate view and supporting strategic decisionmaking and providing guidance about sub-sequent operational decisions (Lyneis et al., 2001; Lyneis and Ford, 2007; Sterman et al., 2015). Dynamic models of projects help us to understand the dynamics of system components and variables over time and provide insights for best practice in project management (Rodrigues, 2001). According to Ford and Lyneis (2013), the application of system dynamics to project management can be classified into the following three groups: (1) project canonical structures such as the rework feedback loop (Lyneis and Ford, 2007), (2) project dynamics of disruptions such as delays in design and insufficient collaboration among the partners (Sterman et al., 2015), and (3) project domain such as construction and digital projects (Ford and Lyneis, 2013). Comprehensive surveys of system dynamics literature on project management can be found in Lyneis and Ford (2007), Pargar et al. (2019), Rodrigues and Bowers (1996), and Sterman et al. (2015).

In this study, we use the system dynamics methodology to explore value creation mechanisms

Engineering Project Organization Journal

(C) 2018 Engineering Project Organization Society www.epossociety.org 
by focusing on both endogenous and exogenous drivers of project behaviour. From the endogenous perspective, we explore the interactions among concepts within the boundary of the system that lead to complex behaviours. We also consider value creation through exogenous drivers outside of the model such as project complexity and uncertainty. These exogenous variables are outside (input) variables that affect but are not affected by the system (Jalali et al., 2017). Here, we not only take endogenous and exogenous perspectives but also quantify the feedback mechanisms. The systems dynamics methodology is an analysis method of combining qualitative analysis, quantitative analysis and synthesis reasoning. We develop a stock and flow model (see Sterman, 2000) to analyze the behavior of the system over time and explore the main processes influencing the value creation. The structure of a system dynamics model includes a set of relations between model variables, represented in the form of differential equations. In solving the non-linear equations, the dynamic behaviour of the model is obtained by simulation. Simulation is essentially a step-by-step operation of the model structure over compressed time so that the dynamics of model variables gradually unfold (Barlas, 2009).

\section{Structures Underlying Project Dynamics}

To study system behaviour and provide insights for value creation and delivery in project management implementation phase, we need to focus on project model structures. Barlas (2009) argues that "the structure creates the behaviour." The structure of a system can be defined by the complicated relationships between system variables. The structure of the model represents those aspects of the real structure that modelers believe (or hypothesize) to be important, with respect to the specific problems of concern (Barlas, 2009). In this section, we focus on the structures that have been used to model projects and operate to produce value creation dynamics.

By synthesising existing literature on project management and system dynamics, this paper describes the project model structures in four groups. The four model structure groups are: (1) project team features, (2) project characteristics, (3) project controls and value creation processes, and (4) project remedial actions due to ripple effects. Based on our project management experience and modelling, we believe that the proposed project model structures have captured the majority of the important features to simulate project dynamics on delivering a valuable project outcome and it can be easily adapted to the implementation phase of different project domains such as construction, infrastructure, new product development, and digital projects. In general, each project type has certain characteristics such as complexity and the amount of uncertainty in technology or requirement and it needs certain practices and project team features to deal with these characteristics. Here, we formulated project controls and value creation processes with relevant feedback effects and their interactions for a hypothetical project. While specific project domains might differ in their level of detail with regard to the characteristics of the rework cycle, the complexity of making decisions relevant to rework, redesign and rescheduling, formulations of these processes can be adapted for a specific project domain and is not within the scope of this research.

Figure 1 shows the paper framework as a simulation study to explore value creation processes and the influencing structures (inputs). We provide a system dynamics model in Section 4 to explore the transformation process including the interplay of different value creation processes with their influencing structures and discuss relevant managerial actions and their side effects to improve project value.

In the next sub-sections, we first discuss project characteristics and team features as two (exogenous) structures that are not directly creating value but have a strong influence on value creation processes. In this study, we mainly focused on endogenous dynamics and assumed that the project characteristics (e.g., complexity and uncertainty) and team features will be fixed during the project implementation. These exogenous variables affect the system but are not affected by the managerial actions during the project. We discuss how and 


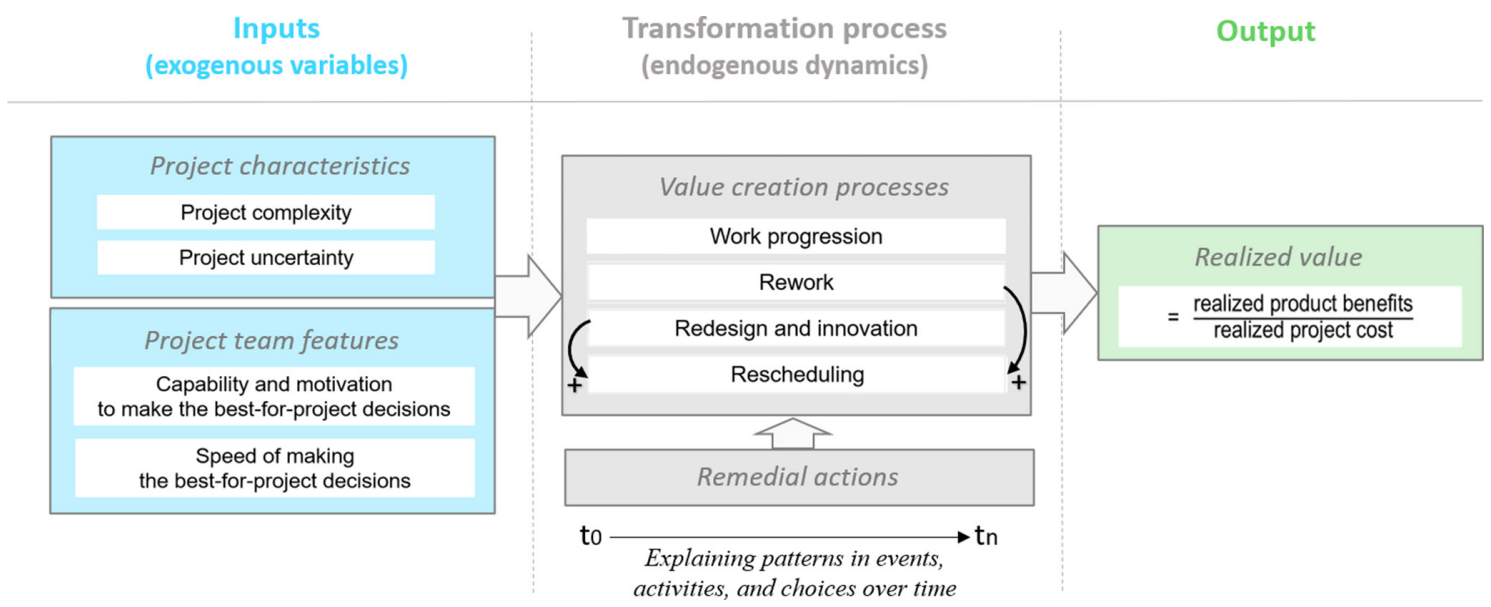

Figure 1 Research frame including value creation processes and the influencing structures.

through which mechanisms these two exogenous input variables would influence the value creation dynamics. Then, we explore the four value creation processes and related remedial actions to avoid their unintended consequences. These four structures are summarized in the stock and flow model with different colors in the next section.

\section{Project Team Features}

Given the project requirements and characteristics, the client/owner(s) selects the project partners by focusing on typical selection criteria such as their competence, offered price, and technical capacity (Lahdenperä, 2009). During the project planning phase, project team coordinates integrative activities that involve communicating, translating, measuring, specifying, reviewing, testing, and monitoring (Scott et al., 2011). Teambuilding activities/events including workshops and conferences are used to facilitate socialisation within the project (Gupta and Govindarajan, 2000; Van Maanen and Schein, 1977; Cousins et al., 2008; Hietajärvi et al., 2017b). Aaltonen and Turkulainen, 2018 show that the use of formal socialisation mechanisms together with informal ones is particularly critical in the planning phase of projects to facilitate mutual trust, commitment, and co-operation among project partners. For example, collocational space among executors and designers to communicate expectations and share useful information and knowledge is a kind of formal socialisation mechanism and informal socialisation mechanism are those in which mainly occurs outside of the workplace.

Based on the existing literature and reports on project management, project team features such as capability and motivation to make the best-forproject decisions together with speed of decisionmaking have a strong influence on delivering a valuable project outcome (Pargar et al., 2019). These features can be developed using various socialisation mechanisms during the planning phase and affect how the project team manages and coordinates tasks during the project implementation phase. Best-for-project decisions are those that mainly serve the interests of the overall project by reducing the project cost or increasing product benefit to deliver valuable product (output) to customer. Project teams often simultaneously use both contractual and relational mechanisms to organize their relationships and make the best-forproject decisions (Cao and Lumineau, 2015). One contractual mechanism is the project commercial model that includes performance incentives set for key performance targets such as schedule and quality. Incentives allow for better alignment of the contracting parties' goals to serve the interests of the overall project and make the best-forproject decisions (Lahdenperä, 2009). A capable project team is able to synchronise tasks and link together resources and processes to achieve desired outcomes (Jennings, 1994).

We define the project team's capability as the project team's resource endowments and the joint 
forces to pursue project values (see Das and Teng, 2002). Project team's motivation shows the level of alignment in partners' interests and preferences (see Hardy and Phillips, 1998; Kogut, 1989). If the project team has enough motivation and capability to discover non-value-adding works (eg, error, waiting) but does not make decisions quickly enough, the opportunity for correcting them will be lost. Therefore, speed of decision-making is another important factor in delivering value in projects. Making quick decisions is related to both high degrees of information sharing and communication among partners and project team authority to make decisions without external approvals. Practices such as last planner workshops and co-location of the team members in a collaborative space improve the coordination of work, knowledge sharing, communication and speed of decision-making processes (Hietajärvi et al., 2017b). Depending on project team performance in the development phase, as the partners collaborate and bring invaluable resources, there will be an initial level of capability and motivation at the beginning of the implementation phase. An important challenge for project teams is to preserve and persistently drive a collaborative culture in the implementation phase (Rooney, 2009; Ross, 2009). However, there is a research gap in the dynamics of the project team's features and its influencing factors. In this study, we assumed that the project team features will be fixed during the project implementation.

\section{Project Characteristics}

An important cause for cost overruns and schedule delays in most projects can be found in unrealistic project plans (Flyvbjerg et al., 2003). Usually, project plans do not properly account for some of the intrinsic difficulties in managing projects such as high uncertainty, high interdependency between activities, and numerous stakeholders (Capka, 2004). Project managers can adapt their decision-making approach to maximise performance by understanding the project's levels of complexity and uncertainty.

In project management research, complexity and uncertainty are two constructs that are not clearly defined and differentiated (Ahern et al., 2014; Daniel and Daniel, 2018; Geraldi et al., 2011). Recent literature on complexity and uncertainty management in projects calls for the development of a non-deterministic paradigm of project management based on principles of emergence (Daniel and Daniel, 2018). Typically, project complexity as the inherent characteristics of a project takes a variety of forms such as structural complexity, uncertainty, dynamics, pace and socio-political complexity (Ahern et al., 2014; Geraldi et al., 2011; Lessard et al., 2014). Complex projects are not necessarily vague or unpredictable, but the vast number and variety of elements and relationships are not easily coordinated (Campbell, 1988). In this paper, the project complexity level is defined by dependency among tasks ( $\mathrm{Lu}$ et al., 2015). Managers involved in complex projects must face difficult events that influence each other and produce causality relations that are not clear for decision-makers (Kauffman, 1993). Project administrators must have the appropriate capability in response to complexity such as differentiation, subdividing the work into simpler, more tractable components (Scott et al., 2011).

Another challenge of project administration is to manage uncertainty. Uncertain events in one part of a project can trigger chain reactions of unanticipated, interconnected events (Scott et al., 2011). There are various types of uncertainties exist during the project implementation phase (Galli, 2018; Pruyt, 2007). The discovery of more innovative solutions related to product features and working methods in the planning phase could reduce project uncertainty in the implementation phase. Uncertainty could provide opportunities for innovation to redesign product features to increase benefits or to decrease costs. Uncertainty could also bring unplanned changes that result in the need to flexibly reassign resources and reschedule work. Project team must have coordination capability in response to uncertainty to assure the project is completed as planned.

\section{Project Controls and Value Creation Processes}

The value-creation process in project execution is complex especially when multiple stakeholders are involved in delivering and capturing project value (Bowman and Ambrosini, 2000). Project team often discover opportunities for increased value during 
project implementation by capturing the various stakeholders' views (Ang and Killen, 2016; Lechler and Edington, 2013). Here, we defined value from an economic perspective by transforming the exploited opportunities relevant to schedule, quality, and other non-financial benefits into monetary terms.

Each project consists of a collection of tasks that needs to be performed according to the agreed key performance targets during the implementation phase. A project team may decide to accelerate the project to meet the deadline by aggressively scheduling tasks, thereby allowing less time to complete each task. This is known as schedule pressure in the literature (Nepal et al., 2006). Schedule pressure is defined as the tension caused by the gap between the time left before the scheduled completion date and the project team's perception of the needed time to complete the project with the currently allocated resources (Yaghootkar and Gil, 2012). Accordingly, cost pressure is the tension caused by the gap between the required cost to complete the project with current practices and the actual budget left from the agreed completion cost.

It is essential to model the controlling feedback loops to reduce the gaps between performance targets and project performance. Analysing the control of dynamic systems is the aim of applying system dynamics to project management. Here, we analyse how a project team can deliver a valuable product by decreasing project costs and increasing its benefits through the following four distinct but interrelated processes: work progression, rework, redesign and innovation, and rescheduling.

\section{Work progression process}

The work progression process represents the application of resources to complete tasks or work packages and meet the deadline. Given the issues relevant to poor quality, productivity, and wastes, work progression shows how efficiently tasks flow from the stock of work to do to the stock of work completed correctly. The completion of work (rate of work progress) depends on available resources, quality, and productivity. In the work progression process, project teams make two common actions to meet the deadline: working faster and increasing resources (based on Lyneis and Ford, 2007).
An increase in schedule pressure, by allowing less time to complete each task, leads to a faster completion of work (which increases productivity). However, schedule pressure invites many negative ripple effects on a workers' performance (due to a higher intensity of work) which could ultimately reduce the productivity and quality of their work. Nepal et al. (2006) extensively analysed the dynamic effects of schedule pressure on project performance. Research in managerial psychology explained the relationship between work stress and performance in completing a task by an inverse U-shaped curve, which is known as the Yerkes-Dodson Law (Corbett, 2015). It has been argued that schedule pressure acts as a major stressor to workers and productivity measures the efficiency of work performance, therefore, the above relationship equally holds between schedule pressure and productivity (Nepal et al., 2006). The performance increases upon increasing the degree of schedule pressure up to a certain point, beyond which the performance decreases. This relationship is different for various type of task complexity. The maximum level of performance is obtained for a simple task at a lower level of pressure in comparison with difficult tasks (Myers and DeWall, 2017; Wickens and Hollands, 2000). When schedule pressure is too low, the performance is affected because of a lack of urgency, awareness or boredom. On the other hand, when there is too much pressure, the expected performance may be difficult to achieve because of frustration or motivation loss (Rastegary and Landy, 1993; Svenson and Benson, 1991; Wickens and Hollands, 2000). In addition to schedule pressure, the capability and motivation to coordinate work could also influence productivity and when it is at a sufficiently high level, resources can spend more time on doing tasks and productivity will be increased.

Another managerial action is to employ additional resources to improve the project performance and meet targets. Various side effects of this action have been studied in the literature (Godlewski et al., 2012; Lyneis and Ford, 2007; Taylor and Ford, 2006). In this research, we mad an simplifying assumption by adding resources with enough experience to the project team to ensure the 
success of the project and not included the wellstudied unintended effects of adding resources such as decreasing productivity and increasing errors due to inexperience workforce, communication difficulties and congestion.

\section{Rework process}

The rework process is at the heart of system dynamics project models (Rahmandad and $\mathrm{Hu}$, 2010). Rework is a common practice to control the quality of the project through discovery and correction of tasks that were incorrectly implemented the first time (also known as defective works or errors). The error generation rate, which is dependent on the capability of the project team to perform work with high quality, determines how much work is defective. In the rework process, the errors must be first discovered before they can be corrected. Almost all dynamic models in project management have some form of rework cycle (Love and Edwards, 2004; Lyneis et al., 2001). The current formulations for the rework assume that the time needed to discover it is the primary influencing factor on rework discovery (Cooper, 1993; Rahmandad and $\mathrm{Hu}, 2010$ ) and all the discovered errors will be corrected. However, in many real-world projects some errors remain undiscovered, actual progress are overestimated, and reporting of errors are discouraged (Rodrigues and Bowers, 1996; Lyneis et al., 2001). Error discovery and correction is dependent on the project team's capability and motivation to monitor and reveal the errors information and efficiency of project team's decision-making. In the rework process, we considered the negative effects of schedule pressure and undiscovered errors on the quality: haste makes waste and errors on error (based on Ford and Sterman, 2003; Lyneis et al., 2001). In this paper, two new stocks called "work completed incorrectly" and "known errors" are introduced typical rework cycle (see Cooper, 1993) to better explain how project team's capability, motivation, and speed of decision-making impact the effectiveness of the rework process. Work completed incorrectly is the consequence of delays in discovering errors and the decision to correct them. The fraction of work completed correctly at the end of the project can be used as a measurement tool for project quality.

\section{Redesign and innovation process}

Uncertainty may create opportunities for the project (Chapman and Ward, 2004). In the classic project management paradigm, opportunity identification and exploitation to maximise value is not considered as a project management activity (Lechler et al., 2012). Lechler et al. (2012) point to a research gap in the current literature by stating that "the nature and significance of value-related opportunities stemming from uncertainty on the project level is not well understood". Project opportunities are situations in which additional value can be created in the project execution phase if they are identified and exploited, like, for example finding innovative solutions to add product features or using the project deliverables to other purposes (Eskerod et al., 2018).

Due to the project uncertainty, all potential opportunities cannot be discovered during the planning phase (DeBarro et al., 2015). Project team can facilitate the promotion of innovative design by arranging various workshops to support innovative solutions through collaboration and knowledge integration among the project partners (Manley et al., 2009). The redesign and innovation process is a practice to get the most out of the value-related opportunities during the project implementation phase. In the redesign and innovation process, we considered two short-term impacts of innovative solutions: innovation can decrease project costs and innovation can increase product benefits (based on Pargar et al., 2019). This process can decrease the project cost by improving work methods and eliminating non-value-adding works. Non-valueadding tasks such as transportation, inventory, and set-up generate costs but do not increase the product benefits. The innovation process can also increase the product benefits by improving safetyrelated targets, the usability of the product and the public image of the project by redesigning product features. The innovative solutions to improve product features increase the product benefits without changing the scope of project and increasing project costs. 
coordinate processes with one another to deliver valuable outputs.

\section{Project Remedial Actions Due to Ripple Effects}

Project administrators can yield the agreed key performance targets of the project by considering various project controls and value creation processes. In the previous sub-section, we have discussed the short-term benefits of adding extra resources, redesigning product features, and performing rework to meet the key performance targets. However, control efforts could have unintended consequences and their long-term impacts can be detrimental. The primary side effects of project control efforts are known as ripple effects in the literature (Lyneis and Ford, 2007). For example, adding extra resources can increase the rate of work progress and decreases schedule pressure. However, work progression rate depends on resource level and productivity and by adding resources, we might not get the most out of the effect of schedule pressure on increasing productivity due to the reduction of schedule pressure. Adding resources can also lead to higher cost pressure in the long-term. The short-term benefit of the rework process is to prevent reduction in product benefits by minimising the work completed incorrectly. However, rework is also a major contributor to cost overruns and schedule delays. Another example is the decision to redesign which may cause disruptive changes and schedule delays if the project team is not capable of systematic implementation of new ideas, redesigning product features and working methods.

Project administrators are usually faced with the management of work progress in the face of schedule pressure and cost pressure in a dynamic environment with uncertainties. Thus project implementation process requires the combination of both proactive and reactive decisions by involving foresight to cope with uncertainties and remedial actions to interact with their implementation context throughout the system's lifetime. Ahern et al. (2014) point to this perspective as 'bounded planning' and 'interactive problem solving' by claiming that the project value is not fully known in advance and will be updated over time with uncertainty prevailing. Therefore, without comprehensive understanding of the system structure, the full commitment to the project controls 
can be detrimental to project outcome when there is schedule pressure or cost pressure. Project team can reduce the ripple effects of project controls relevant to adding resources, correcting errors, and redesigning product features by redirecting its commitments and reducing resource, rework and redesign decisions. These remedial actions can positively influence the value creation. The feedback loops related to the ripple effects are summarized in Appendix 1-figure 1 .

\section{System Dynamics Model}

In this study, we used system dynamics modelling to analyse value creation processes in a project implementation phase and describe how they evolve during project implementation phase. To fulfil the research aim, we integrated the existing feedback loops and causal relationships in the literature (Ford and Sterman, 1998; Lyneis and Ford, 2007; Pargar et al., 2019) and quantified these mechanisms into a detailed simulation model. Detailed explanation of quantification of the causal loop diagrams provides insights drawn from complex causal pathways with the aid of computational tools (Jalali et al., 2017). Quantitative model also allows us to quantify the relationship between variables and the outputs of interest to assess the plausibility of dynamic hypotheses.

To fulfil the research aim, we developed a system dynamics model. The developed SD model contributes to the literature by proposing four structures underlying project dynamics and presenting the interrelation among four distinct but interrelated value creation process using a quantitative stock and flow model. Traditional system dynamics applications in project contexts focus on efficient project implementation and dismissed benefit realization. Many system dynamics project management models consider a version of the "rework" and "work progression" cycles. However, they missed the redesign and rescheduling processes and their interrelations to capture the project benefits. In this study, we have also introduced two new states called known errors and work completed incorrectly to better explain how project characteristics and project team features impact the effectiveness of the rework process. Figure 2 below present the system dynamics model in terms of the stockand-flow diagram which can be used to analyse the project values under different scenarios. The variables relevant to project team features, project characteristics and project controls and their side effects are shown by different colours. This model evolved from well-established SD models including those developed by Lyneis and Ford (2007) and Ford and Sterman (1998). The model is constructed and simulated by AnyLogic for windows version 8.1 software. The equations and parameter values of the model are shown in the Appendix. It should be noted that our model is accessible online on AnyLogic Cloud (see Supplementary file 1). Given the discussed project controls, the model is divided into four processes: work progression, rework, redesign and innovation, and rescheduling.

\section{Base Case Model}

In this section, we initialize the model with a hypothetical project to run the experiments. General information about the project scope and characteristics are summarised in Table 1. In this study, we considered the immediate project cost and lifecycle benefits from using the project deliverables over time to calculate the value. We applied some value creation indexes to transform each unit of work done correctly, redesigned product features, and work completed incorrectly into benefits. Table 2 shows the value creation indexes used in the simulation experiments. Each original or redesigned work that has been done correctly increases the benefit of the project, respectively, by $€ 125000$ and $€ 150000(=125000+25000)$. On the other hand, each work that has been done incorrectly (ie, undiscoverable errors, and known errors not corrected) increase the project cost by $€$ 90000 and decrease the project benefit by $€ 5000$.

Our model is based on a number of key assumptions. We developed our model by considering a hypothetical project that includes performing a set of tasks in a given time period with a specific target outturn cost. We began modelling by assuming that the project team features such as capability, motivation, and speed of decision-making are created in the planning phase and their level will not change during the 




Figure 2 Stock-flow diagram of value creation processes in the project implementation phase.

Structures relevant to project team features, project characteristics, project controls, and remedial actions are respectively shown with green, orange, pink and red fonts.

project implementation. We also assumed that project partners assign experienced resources to the success of the project. Therefore, we excluded the well-studied ripple effects of additional resources such as the impact of workforce experience on quality and productivity, and congestion. According to the Yerkes-Dodson Law (Corbett, 2015), we assume that there exists a certain ideal level of schedule pressure at which the performance is optimum (maximum productivity) which is dependent to task complexity. An appropriate level of schedule pressure can increase the work rate, but "too much" or "too little" pressure can be detrimental to productivity (Corbett, 2015; Nepal et al., 2006). We assumed that parameters such as the fraction of work with potential innovation, the fraction of innovation opportunities related to the removal of non-value-adding works, delay in the budget expansion are fixed inputs. The innovative solutions are limited to those that increase the benefits (eg, product features) without increasing the costs. Therefore, scope growth is not considered. Disruption distribution is a random number developed by using a gamma distribution with certain variation coefficients due to its nonnegative nature (Williams, 2004). The benefit 
Table 1 Base case parameter settings

\begin{tabular}{|c|c|}
\hline Parameters & Values \\
\hline \multirow[b]{4}{*}{ Project scope } & The original number of work to do $=2000$ tasks \\
\hline & Scheduled completion time $=55$ weeks \\
\hline & Agreed completion cost $=200 \mathrm{M} €$ \\
\hline & Tender price $=220 \mathrm{M} €$ \\
\hline \multirow[b]{4}{*}{ Project team features } & Initial resources $=40$ resources \\
\hline & Initial productivity $=0.95 \mathrm{task} / \mathrm{resource} / \mathrm{week}$ \\
\hline & Initial quality $=0.95 \mathrm{Dmnl}^{\mathrm{a}}($ error generation rate $=5 \%)$ \\
\hline & Team'capability, motivation and speed of decision-making $=0.9 \in[0,1] \mathrm{Dmnl}^{\mathrm{b}}$ \\
\hline \multirow[b]{2}{*}{ Project characteristics } & Project uncertainty $=0.9 \in[0,1] \mathrm{Dmnl}^{\mathrm{b}}$ \\
\hline & Project complexity $=0.9 \in[0,1] \mathrm{Dmnl}^{\mathrm{b}}$ \\
\hline
\end{tabular}

return for each task on its cost is estimated to be 30\% (Meyer, 2014). The usefulness of any model depends in part on the accuracy and reliability of its output. The validity and reliability of the simulation model to run experiments and analyse policies are evaluated in the next subsection.

\section{Credibility Assessment}

The credibility of the model is achieved by testing its reliability and results in reflecting the real-world in a meaningful way (Richardson and Pugh III, 1981). In purely correlational (black-box) models in which there is no claim of causality in structure, the model is assessed to be valid if its output matches the "real" output within the specified range of accuracy. However, to develop a valid causal descriptive (white-box) model, generating an "accurate" output behaviour is not sufficient; the internal structure of the model needs to be valid to explain the system behaviour (Barlas, 1996).

The validity of the presented model is achieved by conducting various direct/indirect structure tests. The consistency and significance of the system behaviour were tested by setting the model's input parameters to different values and logically explaining project behaviour given the inputs (see section 5.3). In this study, we are not calibrating parameter values based on a specific case to reproduce the historical data. We tuned the model's parameters to ensure its behaviour matches

Table 2 Value creation parameter settings

\begin{tabular}{|l|l|}
\hline Parameters & Values \\
\hline \multirow{3}{*}{ Costs } & $\begin{array}{l}\text { Cost of resources for completing each task by considering the nominal productivity of } \\
\text { resources }=90000 € / \text { task/week }\end{array}$ \\
\hline \multirow{3}{*}{ Benefits } & $\begin{array}{l}\text { Benefits of work done correctly }=125000 € / \text { task (by considering the nominal quality and } \\
\text { assuming the estimated benefit return of each task on its cost is } 30 \%) .\end{array}$ \\
\cline { 2 - 3 } & Benefits redesign product features $=25000 € /$ task \\
\cline { 2 - 3 } & $\begin{array}{l}\text { Losses of work completed incorrectly }=-5000 € / \text { task } \\
\text { Benefits of quick-completion and losses of project delay per time period is given in } \\
\text { Appendix Table A (EVII: effect of completion time on benefit). }\end{array}$ \\
\hline
\end{tabular}

EVII, effect of completion time on benefit. 

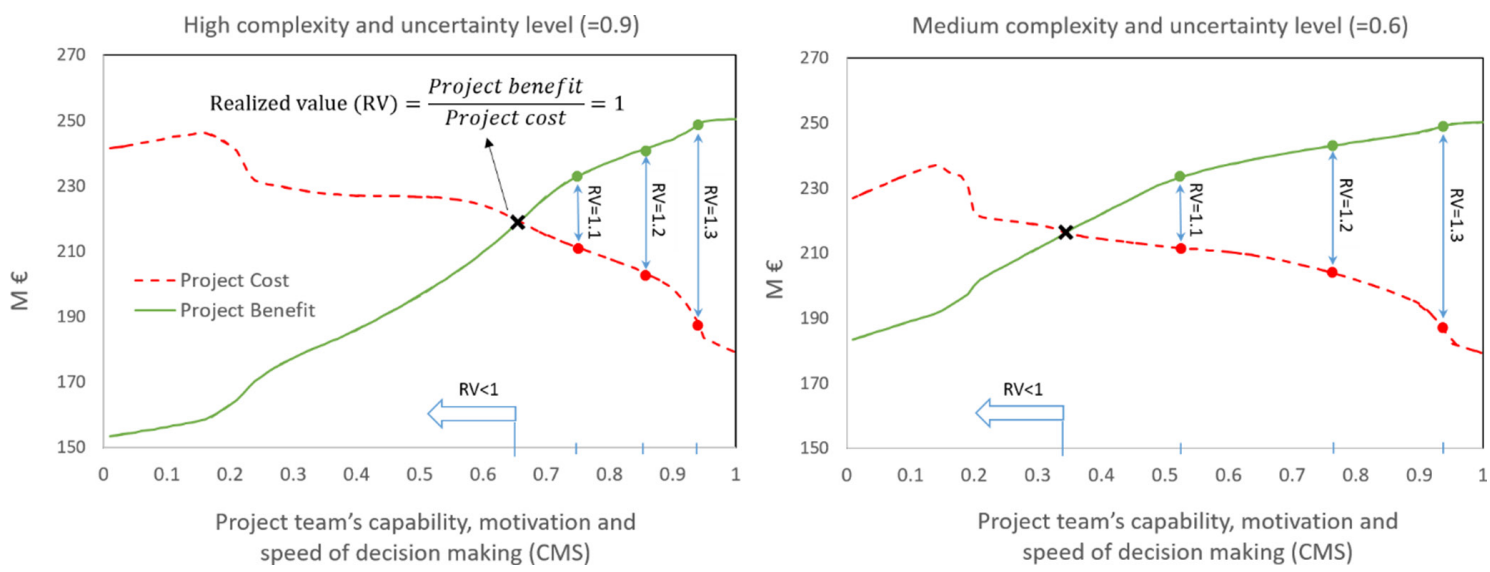

Figure 3 Effect of project team features on the project cost and benefit.

the logical output. The adequacy level of the model boundaries and mechanisms shown in the model were confirmed in discussion with experts and project managers. Extreme condition tests were conducted to disclose subtle flaws that are not easy to capture by direct inspection or baseline behaviour (Sterman, 2000). These tests determine expected behaviours of the model under extreme conditions not seen in the field data; e.g., if total budget is zero, no work can be implemented and no benefit can be created, or if the project team's capability, motivation, and speed of decision-making is at the maximum possible level and project complexity and uncertainty levels are not high, there should be no or a few works wasted. In the formulation of the model, we ensure that stock variables remain nonnegative and represent reality.

We have used the established equations and structures in the literature (Ford and Sterman, 1998; Lyneis and Ford, 2007). We extend the boundary of existing models by modifying the existing rework process and considering the rescheduling and redesign and innovation processes during the project implementation phase. Each equation is tested against different input values to ensure it represented the logic portrayed in the data (Morecroft, 1985). Our analysis in the next section suggests that the model captures the main structure of the project and it is accurate in terms of simulating scenarios to test our dynamic hypotheses with greater care (see Figures 3-6). The model produces different types of dynamic behaviour when parameters are varied and the compatibility level of behaviour generated by the whole model was compared by the proposed behaviour of each subsystem. For example, we changed the structure of the developed system dynamics model by just including the well-known rework process as the benchmark and comparing its results with the model which includes innovation and rescheduling processes. The dimensions of all variables in every equation were reviewed and the dimensions of two sides of all equations were in balance. Validation is a relative concept and depends on the purpose of use. We used the model for the development of process theory and not a prediction. The feedback structures of the model have been formulated based on existing literature and without empirical data. Thus, in the absence of detailed quantitative data for various project cases, seeking operational advice from the model or generalising the findings should be derived carefully.

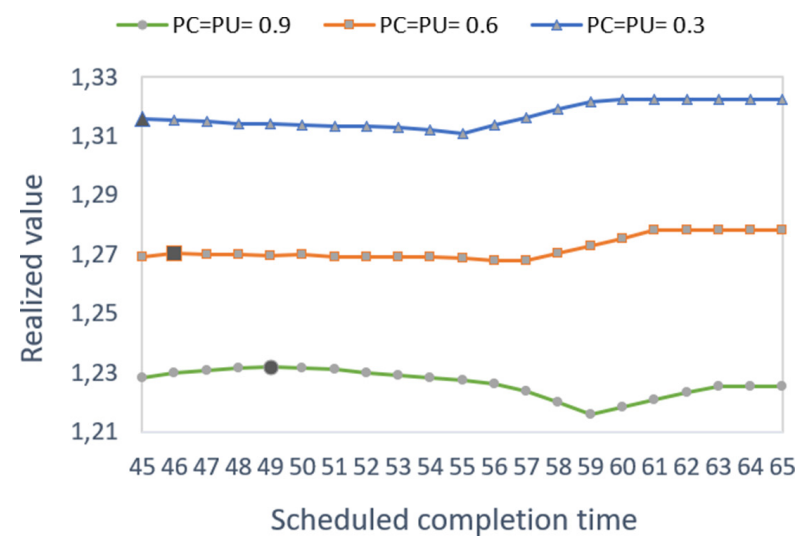

Figure 4 The importance of setting an appropriate completion time on realised value. 

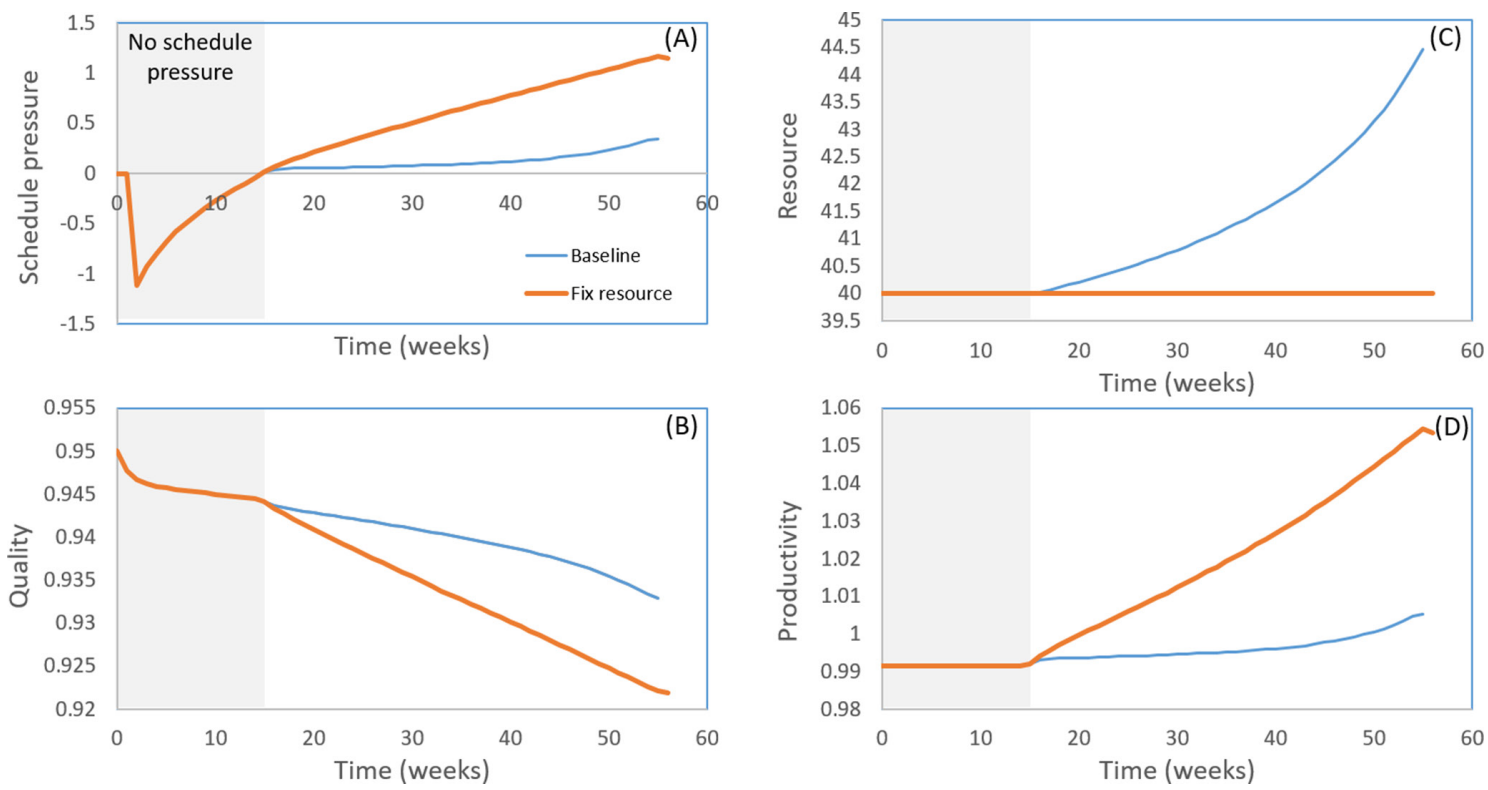

Figure 5 Impact of schedule pressure on quality (B), resource level (C), and productivity (D).

\section{Simulation Experiments and Analysis}

In this section, we focus on the simulation results and analyse the value creation dynamics in the project context. The presented simulation results depict the effects of discussed structures on value creation in the project implementation phase. Our model is generic in the sense that its core processes can be applied to various projects. We mainly focus on understanding the changes in the projects rather than specific numerical values from simulations to maintain a balance between the theorydevelopment nature of our paper and the limits of the real data. We perform five experiments with several scenarios to analyse the effect of project team features, project characteristics, and the project controls and processes on value creation. In the following experiments, specific changes in each scenario are highlighted and the values of other parameters are left as in the base case model shown in Tables 1 and 2 and Appendix Table A. Simulation results are reported after completion of project works and without any time limitation.

This simulation runs help to better understand the leverage points of the system and investigate its behaviour. The simulation model file will be also openly available to ensure the replicability of our results.

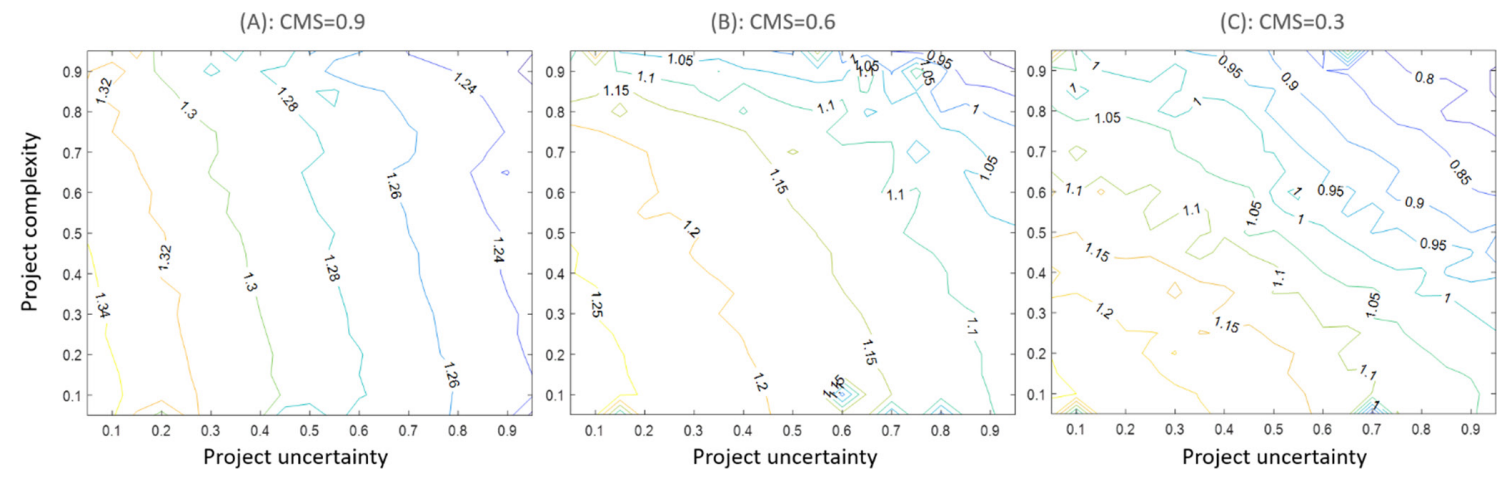

Figure 6 Realised value at different levels of project complexity and uncertainty. 


\section{Impact of Project Control and Pro- cesses on the Project Outcome and the Realized Value}

In this experiment, we consider eight scenarios of an identical project with medium levels of Project Uncertainty and Project Complexity $(\mathrm{PU}=\mathrm{PC}=0.6)$ to illustrate the impact of identified processes on the project outcome. Then, we analyse how each process influences the value creation. It is assumed that the project team has not focused identically to the value creation processes. In each scenario, the level of project team's capability, motivation, and speed of decision-making for the focused processes are fixed at a high level (ie, 0.9) and for the neglected processes are fixed at a low level (ie, 0.3 ). For example, in scenario 2 , we focused on the rework process by assuming that the project team has a high capability and motivation to discover errors and can make fast decisions to correct them. On the other hand, the project team has not developed enough capability and motivation to discover innovative solutions and inexecutable works and cannot make fast enough decisions to redesign product features and working methods and reschedule inexecutable works. The simulation results of these scenarios after completion of project works are reported in Table 3. The developed scenarios show the significance of the redesign and rescheduling processes along with the rework process.

The result of scenario one shows that the benefit of the project is slightly above its cost. Therefore, we cannot deliver valuable output without dealing with the changes during the implementation phase. By considering the redesign process in scenario three and compare it against scenario 1, we observe that the benefit has slightly improved but the cost has significantly increased due to lack of focus on rescheduling. Low level of project team's capability, motivation, and speed of decision-making relevant to rescheduling increases waste and subsequently increases costs through higher schedule pressure and an increase in resources. Therefore, we can conclude that it is better to not redesign if the project team has not enough capability to reschedule works. The same conclusion can be made by comparing scenarios 2 and 5. Nevertheless, these scenarios result in higher benefits due to the higher rate of rework to correct errors (higher project quality). The results of scenarios 6 and 8 show that reduction in commitment and less redesign could be beneficial and lead to a more valuable outcome. We further analysed the reduction in commitments to increase realised value in subsection 5.5. The results shown in Table 3 highlight the importance of value creation processes and their interrelations.

Table 3 Eight scenarios to analyse the significance of the identified processes

\begin{tabular}{|l|l|l|l|l|l|}
\hline Scenarios & $\begin{array}{l}\text { Realised value } \\
\text { (dmnl) }\end{array}$ & $\begin{array}{l}\text { Product benefit } \\
(\mathbf{M} \boldsymbol{(})\end{array}$ & $\begin{array}{l}\text { Project cost } \\
\text { (M€) }\end{array}$ & $\begin{array}{l}\text { Completion } \\
\text { time } \\
\text { (weeks) }\end{array}$ & $\begin{array}{l}\text { Project quality } \\
\text { (dmnl) }\end{array}$ \\
\hline $\begin{array}{l}\text { Scenario 1- Do not focus on rework, } \\
\text { redesign and rescheduling processes. }\end{array}$ & 1.06 & 219.83 & 205.14 & 55.56 & 0.88 \\
\hline Scenario 2- Focus only on rework process & 1.169 & 246.51 & 210.50 & 55.37 & 0.98 \\
\hline Scenario 3- Focus only on redesign process & 1.03 & 220.42 & 211.67 & 55.52 & 0.88 \\
\hline $\begin{array}{l}\text { Scenario 4- Focus only on rescheduling } \\
\text { process }\end{array}$ & 1.161 & 220.40 & 189.55 & 55.34 & 0.88 \\
\hline $\begin{array}{l}\text { Scenario 5- Focus on rework and redesign } \\
\text { processes }\end{array}$ & 1.13 & 246.97 & 217.19 & 55.32 & 0.98 \\
\hline $\begin{array}{l}\text { Scenario 6- Focus on rework and } \\
\text { rescheduling processes }\end{array}$ & 1.28 & 246.60 & 192.48 & 55.36 & 0.98 \\
\hline $\begin{array}{l}\text { Scenario 7- Focus on redesign and } \\
\text { rescheduling processes }\end{array}$ & 1.15 & 220.85 & 191.17 & 55.43 & 0.88 \\
\hline $\begin{array}{l}\text { Scenario 8- Focus on all value creation } \\
\text { processes }\end{array}$ & 1.27 & 247 & 194.45 & 55.33 & 0.98 \\
\hline
\end{tabular}

Engineering Project Organization Journal

(C) 2018 Engineering Project Organization Society

www.epossociety.org 
The relative importance of rework and redesign processes are case-specific and influenced by project characteristics and the commercial model.

\section{Impact of Project Team Features on Value Creation}

Project team features have a strong influence on project performance in terms of delivering value. In this simulation experiment, we evaluate the minimum required level of the project team's capability, motivation, and speed of decisionmaking (CMS) to deliver value in projects with high and medium level of complexity and uncertainty. With a high level of CMS, the project team will be able to get the most out of resources through value creation processes and making the best-forproject decisions on time. The simulation results in Figure 3 show that a project team can deliver considerable value for money (realised value $\geq 1.3$ ) even in very uncertain and complex projects by having high capability, motivation, and speed of decision-making.

As can be seen in Figure 3 below, the benefits of the two projects exceed their costs at different levels of project team's CMS. In a project with a high level of uncertainty and complexity, we could consider the termination of the project if the CMS is below 0.67 (realised value $<1$ ). However, with the same level of CMS (ie, 0.67) in the same project with a medium level of project uncertainty and complexity, the realised value will be 1.15 . In these simulations, the costs for low levels of CMS has a steady growth. However, there is a rapid decrease in cost with the CMS level equals to 0.2. This behaviour is caused by poor implementation of the project and the need for extra budget (eg, delay in the budget expansion) for the CMS level below 0.2 . The steady growth of costs for CMS below 0.2 is due to the fact that having higher CMS leads to a higher rate of rework, redesign and subsequently more need for budget expansion. The results of this kind of analyzes can be also used in the development (planning) phase to evaluate the sufficiency of the current project team's competencies and practices to deal with project complexity and uncertainty and successful implementation of the project.

The developed simulation model also provides the opportunity to evaluate the effect of different parameters relevant to project scope on the project performance in a risk-free world. For example, given the available level of project team's capability and motivation to make the best-for-project decisions together with the speed of decision-making after the planning phase, we can decide about the best levels for completion time and cost in order to maximise the realised value. Figure 4 illustrates the importance of scheduled completion time (lead-time) on the realised value for a project with high levels of project complexity and uncertainty and high levels of project team's CMS. Given the characteristics of the project and project team, the realized value for a complex and uncertain project $(\mathrm{PC}=\mathrm{PU}=0.9)$ will be maximised with the leadtime equal to 49 weeks. By considering the lead time equal to 49 weeks, the project team feels a reasonable level of tension which has a positive impact on productivity and quality. Consequently, the project cost will be reduced by paying for the resources for a shorter period. The increasing pattern of realised value for high lead times (over 59 weeks) is because the project completion time will remain weeks and more benefit related to the schedule will be achieved with the same cost. A similar increasing pattern is observed for other levels of project complexity and uncertainty (i.e. $\mathrm{PC}=\mathrm{PU}=0.6$ or 0.3 ) a bit earlier. The maximum realized value before the increasing pattern will be obtained by setting the lead time equal to 46 and 45 weeks for the medium and low level of project complexity and uncertainty. This is mainly due to the fact that we can get a suitable level of schedule pressure that can increase productivity and adding the required resource to finish the project by the scheduled completion time. According to the Yerkes-Dodson Law, the ideal level of schedule pressure to maximize productivity is dependent to task complexity (Corbett, 2015). For more complex tasks the ideal level of performance reaches at lower level of schedule pressure in comparison with simpler tasks (Nepal et al., 2006). Since the project team has high level of capability, motivation, and speed of decision-making is high $(\mathrm{CMS}=0.9)$ for the three scenarios in Figure 4, the project team reach its best level of performance (the ideal level of schedule pressure) at an earlier scheduled completion time as the project complexity and uncertainty reduces. 


\section{Schedule Pressure and Resource Level as Endogenous Drivers of System Be- havior}

In this experiment, we focus on endogenous drivers of system behaviour to provide a richer understanding of the impact of schedule pressure on productivity, quality, and resource level. To demonstrate, consider two scenarios of an identical project with a high level of project team's capability, motivation, and speed of decisionmaking $(\mathrm{CMS}=0.9)$ and a medium level of project uncertainty and complexity $(\mathrm{PU}=\mathrm{PC}=0.6)$. The only difference between the two simulated scenarios is the possibility to allocate extra resources to the project to finish the project before the scheduled completion time and to reduce the negative ripple effect of schedule pressure. In the baseline scenario, the model can increase the resource level. In the alternative scenario, the resource level is fixed to its initial value (INRES=0). Figure 5 shows the dynamics of system behaviour in terms of schedule pressure, resource level, quality and productivity in the simulated scenarios.

Figure 5(A) shows that without an increase in the resources, the schedule pressure will be higher and the project will be delivered 1.14 weeks after the deadline (which is 55 weeks). If there is a large penalty or value reduction for missing the project deadline, the project team will be more sensitive to delays and will add even more resources to get the project completed on schedule. The benefits of completing the project before the deadline should exceed the extra cost for adding resources. The higher schedule pressure in the fix resource scenario is the main reason for decreased quality of work (see Figure 5(B). As shown in the rework process of Figure 3, schedule pressure results in out-ofsequence work that could generate even more errors (haste make waste). Schedule pressure is also the main driver of adding resources in the work progression process. As can be seen in Figure 5(C), increasing the resource level in the baseline scenario will decrease schedule pressure through increasing work rate and reducing the remaining work. Figure 5(D) shows that productivity is higher in the fixed resource scenario. In fact, due to the high capability and motivation of the project team to coordinate work and a medium level of project complexity, the schedule pressure has an ideal level in which productivity is maximised. Given the commercial model of this hypothetical project and considered complexity for this experiment, when the CMS is high we can deliver more valuable output by not adding resources (the benefits relevant to time and quality cannot compensate the extra cost of resources).

\section{Impact of Project Characteristics on Realized Value}

Here, we analyse the sensitivity of realised value to project complexity and uncertainty at different levels of CMS. We change the values of project complexity and uncertainty to fully assess their potential impacts on the realised value. Drawing these parameters between zero and one with the steps equal to 0.02 and leaving the other parameters as in the base case, we conduct 2500 simulations and measure the realised value. Figure 6 presents, in a contour plot, the impact of project complexity and uncertainty on realised value.

Figure 6(A) shows that the project team with a high level of CMS is able to deal with the project complexity and create reasonable value in each level of project uncertainty. Both project complexity and uncertainty are out of the project team's control but uncertainty is less manageable than complexity with a high level of CMS. In contrast, as can be seen in Figure $6(\mathrm{C})$, the realised value will be highly dependent on project complexity level when the CMS level is low.

\section{Impact of Remedial Actions on Realized Value}

This experiment aims to verify the policy resistance and unintended consequences of project controls to increase resources, correct errors, and redesign product features. We illustrate how a project team can increase the delivered value by reducing the commitments and take remedial actions relevant to rework, redesign, and work progression processes. It is assumed that schedule pressure can cause redesign and rework reductions and cost pressure can cause resource and rework reductions (Love et al., 2011). Here, we consider projects with 
Table 4 Realised value by taking remedial actions and considering reductions in rework, redesign, and resource

\begin{tabular}{|l|l|l|l|l|l|l|}
\hline \multirow{2}{*}{ Scenarios } & \multicolumn{2}{l|}{ PC= $\mathbf{P U}=\mathbf{0 . 6}$} & \multicolumn{3}{l|}{ PC= $\mathbf{P U}=\mathbf{0 . 9}$} \\
\cline { 2 - 8 } & $\mathbf{C M S}=\mathbf{0 . 3}$ & $\mathbf{C M S}=\mathbf{0 . 6}$ & $\mathbf{C M S}=\mathbf{0 . 9}$ & $\mathbf{C M S}=\mathbf{0 . 3}$ & $\mathbf{C M S}=\mathbf{0 . 6}$ & $\mathbf{C M S}=\mathbf{0 . 9}$ \\
\hline No reduction in commitments & 0.96 & 1.12 & 1.26 & 0.76 & 0.92 & 1.22 \\
\hline $50 \%$ reduction in commitments & 0.93 & 1.14 & 1.27 & 0.65 & 0.92 & 1.23 \\
\hline $100 \%$ reduction in commitments & 0.83 & 0.98 & 1.28 & 0.68 & 0.72 & 1.24 \\
\hline
\end{tabular}

two levels for project uncertainty and complexity and analyse the impact of different percentage of rework (REWR), redesign (REDR), and reduction in resource (RESR).

As can be seen in Table 4, when the project team's CMS is high, the realised value increases by more reduction in resource, rework and redesign. Therefore, if there are schedule pressure or cost pressure and the project team has a high level of CMS, the extra benefits achieved by redesign and rework cannot compensate for the extra cost for adding resources and it would be beneficial to have $100 \%$ reduction in commitments. According to the results shown in Table 4, we cannot make a strong conclusion for other cases. The observed nonlinear behavior for a medium level of CMS can be explained using the feedback loops in Appendix 1 -figure 1. Increasing the level of reduction in commitments leads to late project delivery through the "Accept Delay to Avoid Cost Overrun" feedback loop by not adding the required resources (through the "Add Resource" feedback loop). Increasing the level of reduction in commitments also leads to low project quality through the "Accept Less Project Quality" feedback loop by not correcting the errors which eventually reduce the quality (through the "errors on error" feedback loop). Therefore, this reduction in commitments results in a significant reduction in product benefits (relevant to schedule and quality) and subsequently the realized value. Given the project characteristics and project team features, a more detailed analysis is required on how a project manager can increase the realised value. However, the insight gathered might not be generalizable to other projects. To achieve an effective policy, we can use optimisation experiments to finding the optimal combination of conditions (by considering various levels for REWR, REDR, and RESR) resulting in the best possible solution for realised value. The optimisation process consists of repetitive simulations of a model with different case-specific parameters relevant to the project team features and project characteristics.

\section{Policy Discussion}

Given the above results, which highlight the importance of various scenarios to maximise the project value, this section explains some implications that help the accomplishment of this trajectory. The developed system dynamics project model can be used as a test laboratory to analyse various scenarios in a risk-free (simulation) world where it is allowed to try various scenarios, make mistakes, and then implement the best solution in practice. It helps us better understand when managers should improve project quality by correcting errors, improve project benefit by redesigning product features, reduce project cost and time by rescheduling non-value adding works. In addition to value creation processes, managers can significantly improve project performance through efforts to manage their side effects. We analysed various remedial actions that managers should do when a project is likely to not meet the performance targets. For example, when there is a schedule pressure or cost pressure, it might be beneficial to ease performance targets by slipping the scheduled completion time, increasing the budget, accepting a higher fraction of errors in the final product, and taking remedial actions relevant to redesign and work progression processes. By integrating the developed model into traditional concepts and tools (which views a narrow part of the project statically), project management practitioners can better deal with the dynamic complexity of uncertain projects. 
The developed SD model can be also used as a risk management tool to analyse various policy advice discussed in the literature (Lyneis and Ford, 2007; Smith et al., 1993). For example, what is the best approach to getting the project back on track? What is the moderate level of schedule pressure that should be followed to increase performance and is it true on all projects? From a system dynamics perspective, answering these questions is difficult because of the strengths of the feedback loops differ across projects and are dynamic during projects. Each project is different, given the project characteristics and project team features, so based on the real empirical data of one case, we cannot offer specific advice such as "increase resources $\mathrm{x} \%$ while using $\mathrm{y} \%$ rework and redesign". Similar advice can be also found in the literature such as increasing personnel on a project is usually counterproductive. However, there is limited quantitative guidance for the advice offered. More work is needed on how managers can use the insights from the system dynamics models to develop such guidelines for their specific projects. The results of our analysis suggest that spending extra time on the planning phase to further develop project team features results in higher benefits at a lower cost especially in projects with a high level of uncertainty and complexity. The results highlight the importance of employing various value creation processes. Given the current practices and project characteristics, the project manager can measure the realized value at any time during the project implementation and adjust their strategy by finding the best balance between rework, redesign, and resource-related decisions to improve the project performance and get the most valuable output. However, there is always room for improvement in project team features by organizing several pieces of training, workshops, team-building events, and reflection sessions to facilitate socialization within the project and improve project team capability, motivation, and speed of making the best-forproject decisions. In this study, we assumed that the project team features will be fixed during the project implementation, but we have shown the importance of having a high level of CMS through various simulation scenarios.

\section{Conclusion}

Overall, shifting the focus of project management from efficient project implementation to value creation is challenging. Given the project complexity and uncertainty, it is difficult to ensure the stipulated value creation and the purpose of project management discipline is to better understand how to increase the expected benefits without exceeding the planned costs (Eskerod et al., 2018). Project management tools and techniques mainly focus on descriptions of project performance as a consequence of interaction between project implementation results and relevant management efforts through planning and controlling. To deliver beneficial outcomes, the project management professionals and scholars need to know more about the evolution of this interaction over time (Daniel and Daniel, 2018). Majority of research has shed light on static assessments of the practices, characteristics, and outcomes of projects (Walker and Lloyd-Walker, 2015). This paper contributes to current research by developing a system dynamics simulation model to analyse how can a project team respond to changes during the project implementation and produce a valuable outcome. This paper explores value creation dynamics over time by analysing four distinct value creation processes and explaining their interrelations.

In this paper, we integrated the existing feedback loops and causal relationships in the literature of project management and system dynamics (Ford and Sterman, 1998; Lyneis and Ford, 2007; Pargar et al., 2019) and quantified these mechanisms into a detailed simulation model to analyse value creation and delivery in project execution phase. To study system behaviour and provide insights for value creation, we need to focus on project model structures. The developed simulation model considered four structures underlying project dynamics: project team features, project characteristics, project controls and value creation processes, and project remedial actions due to ripple effects. The developed model considers four distinct but interrelated value creation processes: adjust work capacity to complete work according to the plans (work progression process), increase product benefits by correcting errors

Engineering Project Organization Journal

(C) 2018 Engineering Project Organization Society www.epossociety.org 
(rework process), increase product benefit through innovative solutions relevant to product features and reduce project costs by redesigning working methods (redesign and innovation process), and decrease inexecutable work to reduce costs relevant to changes in project plans (rescheduling process). We use the model to simulate various scenarios that show the significance of value creation processes and their influencing structures in terms of delivering value using stack-andflow diagram. The simulation results suggest that managers need to understand the long- and shortterm consequences of their actions and have a holistic view of the value creation processes and look beyond a single process. Simulation results show how endogenous and exogenous drivers of system behaviour unfold over time and provide a richer understanding of the effect of various model structures on value creation. The results also show that adjusting project control decisions by remedial actions is necessary to ensure that the project's value creation goals are met.

We developed an online simulation tool that can be used as a test laboratory to experiment with various scenarios and provides a transparent interpretation for project managers to use project controls and remedial actions effectively. The model we develop is stylistic and adaptable for different projects considering their delivery methods and application areas. The developed system dynamics model is based on existing literature and explains theoretically the dynamics of value creation in the project context. One direction for future research is to empirically examine the model using real data for various project cases. By performing more numerical work with empirical data, we can develop a generalizable insight for particular projects. A limitation of the research is the assumption that the project team features developed during the project planning phase will remain constant during the implementation phase. There is a lack of understanding of the dynamics of project team features over the project life cycle. More research is required to make the exogenous variables endogenous by analyzing/measuring the project team's capability and motivation to make best-for-project decisions and how various factors such as socialization mechanisms, realized value, and project performance affect them. The impact of commercial models on value captured by all parties should also be further explored. The captured value for a wide range of stakeholders could influence the project team's motivation to make the best-forproject decision and they might behave differently.

In this study, we focused on the economic dimension of value and set up an economic framework within which we can properly understand the cost differences between alternatives under consideration by quantifying the overall economic impact of project decisions such as rework, redesign, and reschedule in monetary terms. Future researchers could investigate the impacts of probabilistic value creation parameter settings as well. We acknowledge other dimensions of value but more studies are required to better understand the benefits of its intangible elements, for example, reputation, learning, collaborative arrangement, and related features such as trust, commitment, and cooperation. Future studies could analyze how different project delivery methods influence the realized value. For example, a project alliance emphasizes the development of shared collaborative culture, knowledge integration arrangements, and flow of information that support project team's capability, motivation, and speed of decision-making. One direction for extending the published online model is to consider simulation steps to be able to modify project controls and remedial actions during the project implementation. Another direction for future research is to develop a simulation model that covers a project's entire lifecycle. Consequently, the project manager can enhance project value by improving project team features given the project characteristics and analyzing the decisions relevant to transition from planning to implementation phase such as the shifting time and the performance level agreements.

\section{References}

Aaltonen, K. and Turkulainen, V. (2018), “Creating relational capital through socialization in project alliances", International Journal of Operations \& Production Management, Vol. 38 No. 6 1387-1421. 10.1108/IJOPM-02-2017-0091

Ahern, T., Leavy, B. and Byrne, P.J. (2014), “Complex project management as complex problem solving: 
a distributed knowledge management perspective", International Journal of Project Management, Vol. 32 No. 8, pp. 1371-1381.

Alliance Executive Team. (2018), "Rantatunneli alliance project. Value for money report, project implementation stage", Tampere City, Finnish Transport Agency, Lemminkäinen Infra, Saanio and Riekkola, A-Insinöörit Suunnittelu, Tampere.

Ang, K.C.S. and Killen, C. (2016), "Multi-stakeholder perspectives of value in project portfolios". 16th Annual Conference of the European Academy of Management (EURAM) Conference 2016. Paris: European Research and Management Conference.

Aritua, B., Smith, N.J. and Bower, D. (2009), "Construction client multi-projects - a complex adaptive systems perspective", International Journal of Project Management, Vol. 27 No. 1, pp. 72-79. 10.1016/j.ijproman.2008.02.005

Barlas, Y. (1996), "Formal aspects of model validity and validation in system dynamics", System dynamics review, Vol. 12 No. 3, pp. 183-210.

Barlas, Y.. ed (2009). System Dynamics. vol. 1 EOLSS Publications: .

Boateng, P., Chen, Z., Ogunlana, S. and Ikediashi, D. (2012), "A system dynamics approach to risks description in megaprojects development", Organization, Technology \& Management in Construction: An International Journal, Vol. 4 No. 3, pp. 593-603. 10.5592/otmcj.2012.3.3

Bowman, C. and Ambrosini, V. (2000), "Value creation versus value capture: towards a coherent definition of value in strategy", British Journal of Management, Vol. 11 No. 1, pp. 1-15. 10.1111/14678551.00147

Browning, T.R. (2014), “A quantitative framework for managing project value, risk, and opportunity", IEEE Transactions on Engineering Management, Vol. 61 No. 4, pp. 583-598. 10.1109/ TEM.2014.2326986

Campbell, D.R. (1988), "Collaboration and contradiction in a research and Staff-Development project", Teachers College record, Vol. 90 No. 1, pp. 99-121.

Cao, Z. and Lumineau, F. (2015), "Revisiting the interplay between contractual and relational governance: a qualitative and meta-analytic investigation", Journal of Operations Management, Vol. 33-34 No. 1, pp. 15-42. 10.1016/j. jom.2014.09.009

Capka, J.R. (2004), Megaprojects-they are a different breed. vol. 68. pp. 2-9.

Chapman, C. and Ward, S. (2004), "Why risk efficiency is a key aspect of best practice projects", Interna- tional Journal of Project Management, Vol. 22 No. 8, pp. 619-632. 10.1016/j.ijproman.2004.05.001

Chih, Y.-Y. and Zwikael, O. (2015), "Project benefit management: a conceptual framework of target benefit formulation", International Journal of Project Management, Vol. 33 No. 2, pp. 352-362. 10.1016/j. ijproman.2014.06.002

Cousins, P.D., Lawson, B. and Squire, B. (2008), "Performance measurement in strategic buyer-supplier relationships: the mediating role of socialization mechanisms", International Journal of Operations \& Production Management, Vol. 28, pp. 238-258. https://doi.org/10.1108/01443570810856170

Cooper, K.G. (1993), “The rework cycle: benchmarks for the project manager", Project Management Journal, Vol. 24 No. 1, pp. 17-21.

Corbett, M. (2015), "From law to folklore: work stress and the Yerkes-Dodson law", Journal of Managerial Psychology, Vol. 30 No. 6, pp. 741-752. 10.1108/ JMP-03-2013-0085

Daniel, P.A. and Daniel, C. (2018), “Complexity, uncertainty and mental models: from a paradigm of regulation to a paradigm of emergence in project management", International Journal of Project Management, Vol. 36 No. 1, pp. 184-197. 10.1016/j. ijproman.2017.07.004

Das, T.K. and Teng, B.-S. (2002), "The dynamics of alliance conditions in the alliance development process", Journal of Management Studies, Vol. 39 No. 5, pp. 725-746. 10.1111/1467-6486.00006

Davis, J., Eisenhardt, K. and Bingham, C. (2007), "Developing theory through simulation methods", Academy of management review, Vol. 32 No. 2, pp. 480-499.

DeBarro, T., MacAulay, S., Davies, A., Wolstenholme, A., Gann, D. and Pelton, J. (2015), "Mantra to method: lessons from managing innovation on Crossrail, UK". Proceedings of the Institution of Civil Engineers-Civil Engineering, 168. vol. 168. pp. 171-178, (11). 10.1680/cien.15.00008

Eskerod, P., Ang, K. and Andersen, E.S. (2018), "Increasing project benefits by project opportunity exploitation", International Journal of Managing Projects in Business, Vol. 11 No. 1, pp. 35-52. 10.1108/IJMPB-07-2017-0089

Flyvbjerg, B., Bruzelius, N. and Rothengatter, W. (2003), Megaprojects and risk: An anatomy of ambition. Cambridge, UK: Cambridge University Press.

Ford, D.N. and Lyneis, J.M. (2013), “Applying System Dynamics to Project Management. Virtual issue of System Dynamics Review”, available at: https:// onlinelibrary.wiley.com/page/journal/10991727/

Engineering Project Organization Journal

(C) 2018 Engineering Project Organization Society www.epossociety.org 
homepage/VirtualIssuesPage.html\#Applying [Apr 2018].

Ford, D.N. and Sterman, J.D. (1998), “Dynamic modeling of product development processes", System Dynamics Review, Vol. 14 No. 1, pp. 31-68. 10.1002/(SICI)1099-1727(199821)14:1<31::AIDSDR141>3.0.CO;2-5

Ford, D.N. and Sterman, J.D. (2003), "The Liar's Club: Concealing Rework in Concurrent Development", Concurrent Engineering, Vol. 11 No. 3, pp. 211219. 10.1177/106329303038028

Fuentes, M., Smyth, H. and Davies, A. (2019), “CoCreation of value outcomes: a client perspective on service provision in projects", International Journal of Project Management, Vol. 37 No. 5, pp. 696-715. 10.1016/j.ijproman.2019.01.003

Galli, B.J. (2018), "The future of economic decision making in project management", IEEE Transactions on Engineering Management, Vol. 67 No. 2 396-413. 10.1109/TEM.2018.2875931

Geraldi, J., Maylor, H. and Williams, T. (2011), "Now, let's make it really complex (complicated) A systematic review of the complexities of projects", International Journal of Operations \& Production Management, Vol. 31 No. 9, pp. 966-990. $10.1108 / 01443571111165848$

Godlewski, E., Lee, G. and Cooper, K. (2012), “System dynamics transforms fluor project and change management", Interfaces, Vol. 42 No. 1, pp. 17-32. 10.1287/inte. 1110.0595

Gupta, A.K. and Govindarajan, V. (2000), "Knowledge flows within multinational corporations strategic", Management Journal, Vol. 21, pp. 473-496. https://doi.org/10.1002/(SICI)1097-0266(200004) 21:4<473::AID-SMJ84>3.0.CO;2-I

Hardy, C. and Phillips, N. (1998), "Strategies of engagement: lessons from the critical examination of collaboration and conflict in an Interorganizational domain", Organization Science, Vol. 9 No. 2, pp. 217-230. 10.1287/orsc.9.2.217

Harrison, R., Carroll, G. and Carley, K. (2007), "Simulation modeling in organizational research", Academy of management review, Vol. 32 No. 4, pp. 1229-1245.

Hietajärvi, A.-M., Aaltonen, K. and Haapasalo, H. (2017a), "Opportunity management in large projects: a case study of an infrastructure alliance project", Construction Innovation, Vol. 17 No. 3, pp. 340-362. 10.1108/CI-10-2016-0051

Hietajärvi, A.-M., Aaltonen, K. and Haapasalo, H. (2017b), "What is project alliance capability?" International Journal of Managing Projects in
Business, Vol. 10 No. 2, pp. 404-422. 10.1108/ IJMPB-07-2016-0056

Jalali, M.S., Rahmandad, H., Bullock, S.L., Lee-Kwan, S.H., Gittelsohn, J. and Ammerman, A. (2017), “Dynamics of intervention adoption, implementation, and maintenance inside organizations: the case of an obesity prevention initiative", Social Science \& Medicine, Vol. 224 No. 1-2, pp. 67-76. 10.1016/j. socscimed.2018.12.021

Jennings, N. (1994), Cooperation in industrial multiagent systems. vol. 43. Singapore: World Scientific.

Kauffman, S.A. (1993), The origins of order: Selforganization and selection in evolution. USA: Oxford University Press.

Kivilä, J., Martinsuo, M. and Vuorinen, L. (2017), "Sustainable project management through project control in infrastructure projects", International Journal of Project Management, Vol. 35 No. 6, pp. 1167-1183. 10.1016/j.ijproman.2017.02.009

Kogut, B. (1989), “The stability of joint ventures: reciprocity and competitive rivalry", The Journal of Industrial Economics, Vol. 38 No. 2, pp. 183-198. $10.2307 / 2098529$

Koskela, L. (2000), An exploration towards a production theory and its application to construction. Espoo, Finland: VTT Technical Research Centre of Finland.

Lahdenperä, P. (2009), Project alliance. The competitive single Target-Cost approach. vol. 2472. Espoo, Finland: VTT Tiedotteita-Research Notes.

Laursen, M. and Svejvig, P. (2016), "Taking stock of project value creation: a structured literature review with future directions for research and practice", International Journal of Project Management, Vol. 34 No. 4, pp. 736-747. 10.1016/j.ijproman.2015.06.007

Lechler, T. and Edington, B. (2013), The silver lining of project uncertainties: discovering opportunities to enhance project value. New Orleans, LA: Project Management Institute..

Lechler, T.G. and Dvir, D. (2010), “An alternative taxonomy of project management structures: linking project management structures and project success", IEEE Transactions on Engineering Management, Vol. 57 No. 2, pp. 198-210. 10.1109/ TEM.2010.2044441

Lechler, T.G., Edington, B.H. and Gao, T. (2012), "Challenging classic project management: turning project uncertainties into business opportunities", Project Management Journal, Vol. 43 No. 6, pp. 59-69. 10.1002/pmj.21304

Lee, S.H., Peña-Mora, F. and Park, M. (2006), “Dynamic planning and control methodology for strategic and operational construction project manage-

Engineering Project Organization Journal

(C) 2018 Engineering Project Organization Society www.epossociety.org 
ment", Automation in Construction, Vol. 15 No. 1, pp. 84-97. 10.1016/j.autcon.2005.02.008

Lessard, D., Sakhrani, V. and Miller, R. (2014), “House of project Complexity - understanding complexity in large infrastructure projects", Engineering Project Organization Journal, Vol. 4 No. 4, pp. 170-192. $10.1080 / 21573727.2014 .907151$

Liu, S.-S. and Shih, K.-C. (2009), "Construction rescheduling based on a manufacturing rescheduling framework", Automation in Construction, Vol. 18 No. 6, pp. 715-723. 10.1016/j.autcon.2009.02.002

Locatelli, G., Mancini, M. and Romano, E. (2014), "Systems engineering to improve the governance in complex project environments", International Journal of Project Management, Vol. 32 No. 8, pp. 1395-1410. 10.1016/j.ijproman.2013.10.007

Love, P.E. and Edwards, D.J. (2004), "Forensic project management: the underlying causes of rework in construction projects", Civil Engineering and Environmental Systems, Vol. 21 No. 3, pp. 207-228.

Love, P.E., Teo, P., Davidson, M., Cumming, S. and Morrison, J. (2016), "Building absorptive capacity in an alliance: process improvement through lessons learned", International Journal of Project Management, Vol. 34 No. 7, pp. 1123-1137.

Love, P.E.D., Davis, P.R., Chevis, R. and Edwards, D.J. (2011), "Risk/reward compensation model for civil engineering infrastructure alliance projects", Journal of Construction Engineering and Management, Vol. 137 No. 2, pp. 127-136. 10.1061/(ASCE) CO.1943-7862.0000263

Lu, Y., Luo, L., Wang, H., Le, Y. and Shi, Q. (2015), "Measurement model of project complexity for large-scale projects from task and organization perspective", International Journal of Project Management, Vol. 33 No. 3, pp. 610-622.

Lyneis, J.M., Cooper, K.G. and Els, S.A. (2001), "Strategic management of complex projects: a case study using system dynamics", System dynamics review, Vol. 17 No. 3, pp. 237-260.

Lyneis, J.M. and Ford, D.N. (2007), "System dynamics applied to project management: a survey, assessment, and directions for future research", System Dynamics Review, Vol. 23 No. 2-3, pp. 157-189. 10.1002/sdr.377

MacDonald, C., Walker, D.H.T. and Moussa, N. (2012), "Value for money in project alliances", International Journal of Managing Projects in Business, Vol. 5 No. 2, pp. 311-324. 10.1108/17538371211214969

Manley, K., McFallan, S. and Kajewski, S. (2009), "Relationship between construction firm strategies and innovation outcomes", Journal of construction engineering and management, Vol. 135 No. 8, pp. 764-771.

Martinsuo, M., Klakegg, O.J. and van Marrewijk, A.H. (2019), "Introduction: delivering value in projects and project-based business", International journal of project management, Vol. 37 No. 5, pp. 631-635.

Meyer, W.G. (2014), "The effect of optimism bias on the decision to terminate failing projects", Project Management Journal, Vol. 45 No. 4, pp. 7-20. 10.1002/pmj.21435

Morecroft, J.D.W. (1985), "Rationality in the analysis of behavioral simulation models", Management Science, Vol. 31 No. 7, pp. 900-916. 10.1287/ mnsc.31.7.900

Morris, P.W. (2013), Reconstructing project management. Hoboken, NJ: John Wiley \& Sons.

Myers, D.G. and DeWall, N. (2017), Psychology in everyday life. Basingstoke, UK: Macmillan.

Nepal, M.P., Park, M. and Son, B. (2006), "Effects of schedule pressure on construction performance", Journal of Construction Engineering and Management, Vol. 132 No. 2, pp. 182-188. 10.1061/ (ASCE)0733-9364(2006)132:2(182)

Pargar, F., Kujala, J., Aaltonen, K. and Ruutu, S. (2019), "Value creation dynamics in a project alliance", International Journal of Project Management, Vol. 37 No. 5, pp. 716-730. 10.1016/j. ijproman.2018.12.006

Pruyt, E. (2007), “August. Dealing with uncertainties combining system dynamics with multiple criteria decision analysis or with exploratory modelling", Proceedings of the 25th International Conference of the System Dynamics Society, Albany, NY.

Rahmandad, H. and Hu, K. (2010), "Modeling the rework cycle: capturing multiple defects per task", System Dynamics Review, Vol. 26 No. 4, pp. 291-315. 10.1002/sdr.435

Rastegary, H. and Landy, F.J. (1993), The interactions among time urgency, uncertainty, and time pressure. In Time pressure and stress in human judgment and decision making. Boston, MA: Springer. pp. 217-239.

Richardson, G.P. and Pugh III, A. I. (1981), Introduction to system dynamics modeling with DYNAMO. New York, NY: Productivity Press Inc.

Rodrigues, A. and Bowers, J. (1996), "System dynamics in project management: a comparative analysis with traditional methods", System Dynamics Review, Vol. 12 No. 2, pp. 121-139. 10.1002/(SICI)10991727(199622)12:2<121::AID-SDR99>3.0.CO;2-X

Rodrigues, A. and Bowers, J. (1996), "The role of system dynamics in project management", Interna-

Engineering Project Organization Journal

(C) 2018 Engineering Project Organization Society www.epossociety.org 
tional Journal of Project Management, Vol. 14 No. 4, pp. 213-220. 10.1016/0263-7863(95)00075-5

Rodrigues, A.G. (2001), "Managing and modeling project risk dynamics a system dynamics-based framework", Fourth European Project Management Conference. 1-7.

Rooney, G. (2009), Project alliancing-the process architecture of a relationship based project delivery system for complex infrastructure projects. ISBN: 1809267.

Ross, J. (2009), Alliance Contracting in Australia: a brief introduction. Melbourne, VIC: PCI Alliance Services.

Samset, K. (2009), "Projects, their quality at entry and challenges in the front-end phase". Making essential choices with scant information. London: Palgrave Macmillan. pp. 18-35.

Scott, W. R., Levitt, R. E., Orr, R. J.. eds (2011). Global projects: Institutional and political challenges Cambridge University Press: Cambridge, UK.

Shenhar, A.J. and Dvir, D. (2007), "Project management research-The challenge and opportunity", Project Management Journal, Vol. 38 No. 2, pp. 93-99. 10.1177/875697280703800210

Smith, B.J., Nguyen, N. and Vidale, R.F. (1993), "Death of a software manager: how to avoid career suicide through dynamic software process modeling", American programmer, Vol. 6, pp. 10-10.

Sterman, J., Oliva, R., Linderman, K. and Bendoly, E. (2015), "System dynamics perspectives and modeling opportunities for research in operations management", Journal of Operations Management, Vol. 39-40 No. 1, pp. 1-5. 10.1016/j.jom.2015.07.001

Sterman, J.D. (2000), Business dynamics: system thinking and modeling for a complex world. Boston: The McGraw- Hill Companies, Inc.

Sum, F.F., de Paula, I.C., Tortorella, G., Pontes, A.T. and Facó, R.T. (2019), "Analysis of the implementation of a lean service in a shared service center: a study of stability and capacity", IEEE Transactions on Engineering Management, Vol. 67 No. 2334 346. 10.1109/TEM.2018.2888837

Svenson, O. and Benson, L. (1991), Framing and time pressure in decision making. Sweden: Department of Psychology, Lund University.

Taylor, T. and Ford, D.N. (2006), "Tipping point failure and robustness in single development projects",
System Dynamics Review, Vol. 22 No. 1, pp. 51-71. $10.1002 /$ sdr.330

Van Maanen, J.E. and Schein, E.H. (1977), Toward a theory of organizational socialization. vol. 1. New York: JIP Press.

Vieira, G.E., Herrmann, J.W. and Lin, E. (2003), "Rescheduling manufacturing systems: a framework of strategies, policies, and methods", Journal of Scheduling, Vol. 6 No. 1, pp. 39-62. 10.1023/A:1022235519958

Walker, D.H.T. and Lloyd-Walker, B.M. (2015), Collaborative Project Procurement Arrangements. Newtown Square, PA: Project Management Institute.

Wickens, C.D. and Hollands, J.G. (2000), Engineering Psychology and Human Performance. 3rd ed. Prentice Hall: Saddle River, NJ.

Williams, T. (2004), "Why Monte Carlo simulations of project networks can mislead", Project Management Journal, Vol. 35 No. 3, pp. 53-61. 10.1177/875697280403500307

Winter, M., Smith, C., Morris, P. and Cicmil, S. (2006), "Directions for future research in project management: the main findings of a UK government-funded research network", International Journal of Project Management, Vol. 24 No. 8, pp. 638-649. 10.1016/j. ijproman.2006.08.009

Winter, M. and Szczepanek, T. (2008), "Projects and programmes as value creation processes: a new perspective and some practical implications", International Journal of Project Management, Vol. 26 No. 1, pp. 95-103. 10.1016/j.ijproman.2007.08.015

Yaghootkar, K. and Gil, N. (2012), “The effects of schedule-driven project management in multiproject environments", International Journal of Project Management, Vol. 30 No. 1, pp. 127-140. 10.1016/j.ijproman.2011.02.005

Zhu, G., Bard, J.F. and Yu, G. (2005), "Disruption management for resource-constrained project scheduling", Journal of the Operational Research Society, Vol. 56 No. 4, pp. 365-381. 10.1057/palgrave.jors. 2601860

Zwikael, O. and Smyrk, J. (2012), “A general framework for gauging the performance of initiatives to enhance organizational value", British Journal of Management, Vol. 23, pp. S6-S22. 10.1111/j.14678551.2012.00823.x 


\section{Appendix}

\section{Appendix 1-Figure 1. Feedback loops relevant to project remedial actions.}

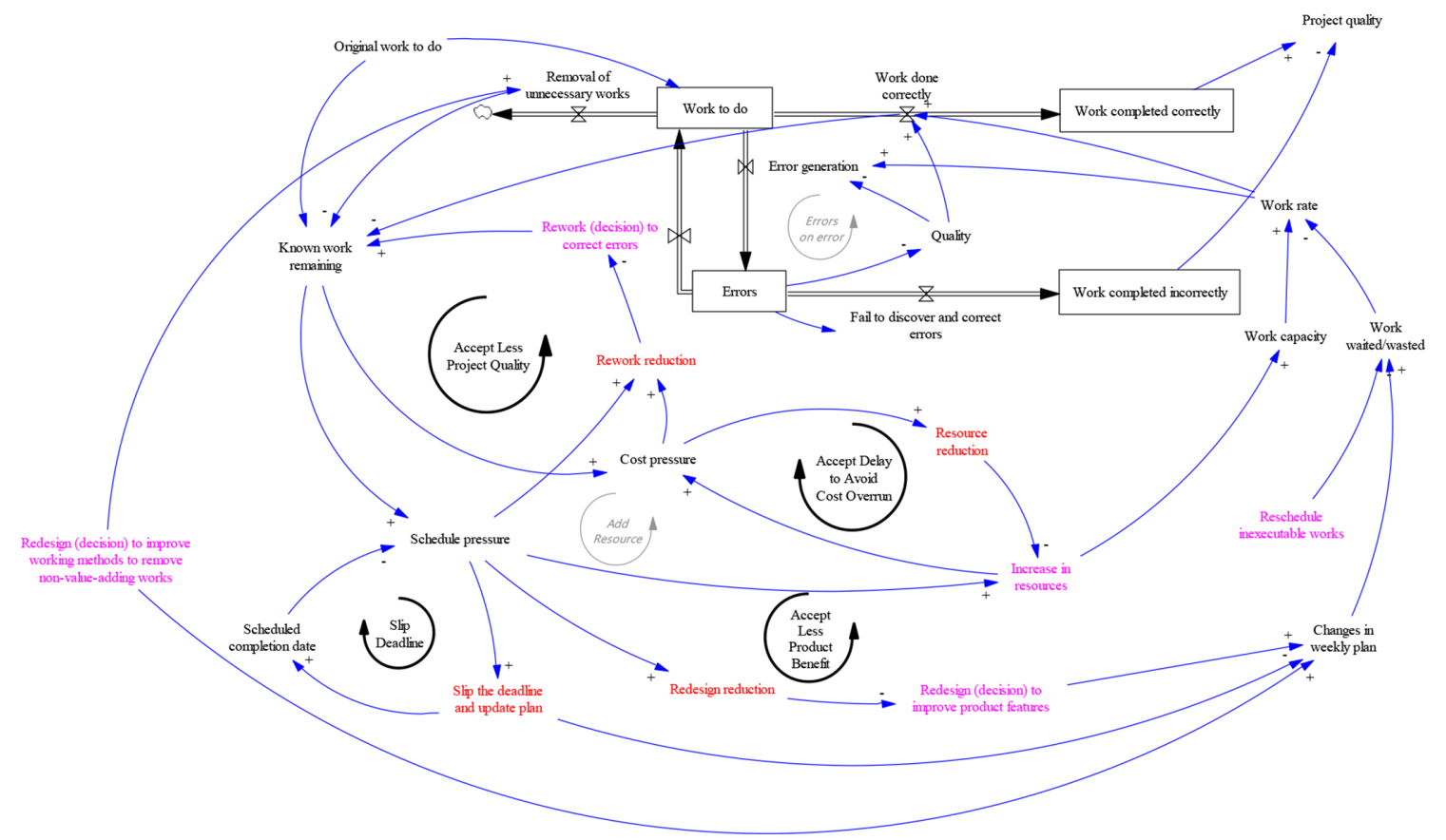

\section{Appendix 1-Table 1. presents all the equations and parameter values used in the developed stock and flow diagram.}

\begin{tabular}{|l||l||l|l|}
\hline Variables: descriptions & Names & Equations & Units \\
\hline $\begin{array}{l}\text { Work To Do: original work to do } \\
\text { in the project }\end{array}$ & WTD & =INTEGRAL(RCE-WDC-EG- RWM, OWTD) & Tasks \\
\hline $\begin{array}{l}\text { Work Completed Correctly: work } \\
\text { completed correctly }\end{array}$ & WCC & = INTEGRAL(WDC, 0) & Tasks \\
\hline $\begin{array}{l}\text { Undiscovered errors: } \\
\text { undiscovered work done } \\
\text { incorrectly }\end{array}$ & UE & = INTEGRAL(EG,-DE-FDE, 0) & Tasks \\
\hline $\begin{array}{l}\text { Known errors: discovered work } \\
\text { done incorrectly }\end{array}$ & KE & = INTEGRAL(DE-RCE-FCE, 0) & Tasks \\
\hline \hline Work Completed Incorrectly & WCI & $=$ INTEGRAL(FDE+ FCE, 0) & Tasks \\
\hline $\begin{array}{l}\text { Resource: resources during } \\
\text { project implementation }\end{array}$ & RES & $=$ INTEGRAL(INRES, IRES) & Resources \\
\hline $\begin{array}{l}\text { Capability, Motivation, and } \\
\text { Speed of decision-making }\end{array}$ & CMS & $=$ ICMS & Dmnl \\
\hline $\begin{array}{l}\text { Project (realised) Cost: costs of } \\
\text { project based on the spending } \\
\text { resources }\end{array}$ & RC & $=$ INTEGRAL(CR, 0) & \\
\hline
\end{tabular}




\begin{tabular}{|c|c|c|c|}
\hline Variables: descriptions & Names & Equations & Units \\
\hline $\begin{array}{l}\text { Project (realised) Benefit: } \\
\text { benefits of project based on the } \\
\text { redesigned work, completion } \\
\text { time, work done correctly and } \\
\text { incorrectly }\end{array}$ & $\mathrm{RB}$ & $=\operatorname{INTEGRAL}(\mathrm{BR}, 0)$ & $\mathrm{M} €$ \\
\hline $\begin{array}{l}\text { Total Budget: the initial estimate } \\
\text { of the project cost before the } \\
\text { planning phase }\end{array}$ & $\mathrm{TB}$ & $=$ INTEGRAL(BER-CR, TP) & $\mathrm{M} €$ \\
\hline Original Work To Do & OWTD & $=2000$ (a constant value) & Tasks \\
\hline Agreed Completion Cost & $\mathrm{ACC}$ & $=200(\mathrm{a}$ constant value $)$ & $\mathrm{M} €$ \\
\hline Tender Price & TP & $=220$ (a constant value) & $\mathrm{M} €$ \\
\hline Scheduled Completion Time & SCT & $=55(\mathrm{a}$ constant value $)$ & Weeks \\
\hline Initial Resource & IRES & $=40($ a constant value $)$ & Resources \\
\hline $\begin{array}{l}\text { Initial Quality: capability to } \\
\text { perform work with high quality }\end{array}$ & IQ & $=0.95$ (a constant value $)$ & Dmnl \\
\hline Initial (nominal) Productivity & IP & $=0.95$ (a constant value $)$ & Dmnl \\
\hline $\begin{array}{l}\text { Project Complexity (work } \\
\text { structure) }\end{array}$ & $\mathrm{PC}$ & $=0.9$ (high:very complex), 0.6 (medium:complex), 0.3 (low: slightly complex) & Dmnl \\
\hline Project Uncertainty (disruption) & $\mathrm{PU}$ & $=0.9$ (high:very noisy), 0.6 (medium: noisy), 0.3 (low:slightly noisy) & Dmnl \\
\hline Rework Reduction & REWR & $=$ a constant value $\in[0,1]$ & Dmnl \\
\hline Redesign Reduction & REDR & $=\mathrm{a}$ constant value $\in[0,1]$ & Dmnl \\
\hline Resource Reduction & RESR & $=$ a constant value $\in[0,1]$ & Dmnl \\
\hline $\begin{array}{l}\text { Initial Capability, Motivation, and } \\
\text { Speed of decision-making }\end{array}$ & ICMS & $=0.9$ (high), 0.6 (medium), 0.3 (low) & Dmnl \\
\hline $\begin{array}{l}\text { Required time for previous errors } \\
\text { to become undiscoverable and } \\
\text { uncorrectable }\end{array}$ & TDCE & $=$ WITH LOOKUP ${ }^{\mathrm{a}}(\mathrm{PC},(0.01,6),(0.1,5),(0.4,4),(0.6,3),(0.8,2),(0.9,1.5),(0.95,1))$ & Weeks \\
\hline $\begin{array}{l}\text { Fraction of Work with Potential } \\
\text { Innovation }\end{array}$ & FWPI & $=0.1(\mathrm{a}$ constant value $)$ & Dmnl \\
\hline $\begin{array}{l}\text { Fraction of Innovation } \\
\text { opportunities related to Removal } \\
\text { of unnecessary works }\end{array}$ & FIR & $=0.1(\mathrm{a}$ constant value $)$ & Dmnl \\
\hline Delay in Budget Expansion & DBE & $=1.5(\mathrm{a}$ constant value $)$ & Weeks \\
\hline Capability and Motivation & $\mathrm{CM}$ & $=\mathrm{CMS}$ & Dmnl \\
\hline $\begin{array}{l}\text { Capability and Motivation to } \\
\text { discover Error per time unit }\end{array}$ & CME & $=\mathrm{CMS}$ & $1 /$ week \\
\hline Speed of Decision-Making & SDM & $=\mathrm{EIV}$ & Weeks \\
\hline Productivity & $\mathrm{P}$ & $=\mathrm{IP}+\mathrm{PC} * \mathrm{EIII}+\mathrm{EVI}$ & $\begin{array}{l}\text { Tasks/ } \\
\text { resource/ } \\
\text { week }\end{array}$ \\
\hline Quality & Q & $=\mathrm{IQ}+\mathrm{PC} *(\mathrm{EI}+\mathrm{EII})$ & Dmnl \\
\hline Nominal Working Capacity & NWC & $=$ RES $*$ IP & $\begin{array}{l}\text { Tasks/ } \\
\text { week }\end{array}$ \\
\hline $\begin{array}{l}\text { Working Capacity: expected } \\
\text { work that can be performed in } \\
\text { each week }\end{array}$ & WC & $=\mathrm{IF}(\mathrm{TB}>0, \mathrm{RES} * \mathrm{P}, 0)$ & $\begin{array}{l}\text { Tasks/ } \\
\text { week }\end{array}$ \\
\hline $\begin{array}{l}\text { Work Done Correctly: rate of } \\
\text { work done correctly in each time } \\
\text { period }\end{array}$ & WDC & $=\mathrm{IF}(\mathrm{TB}>0, \mathrm{WR} * \mathrm{Q}, 0)$ & $\begin{array}{l}\text { Tasks/ } \\
\text { week }\end{array}$ \\
\hline Error Generation & EG & $=\mathrm{IF}(\mathrm{TB}>0, \mathrm{WR} *(1-\mathrm{Q}), 0)$ & $\begin{array}{l}\text { Tasks/ } \\
\text { week }\end{array}$ \\
\hline
\end{tabular}

Engineering Project Organization Journal

(C) 2018 Engineering Project Organization Society

www.epossociety.org 
Engineering Project Organization Journal (September 2021) Volume 10

\begin{tabular}{|c|c|c|c|}
\hline Variables: descriptions & Names & Equations & Units \\
\hline Discovery of Errors & $\mathrm{DE}$ & $=\mathrm{IF}(\mathrm{TB}>0, \mathrm{UE} * \mathrm{CME}, 0)$ & $\begin{array}{l}\text { Tasks/ } \\
\text { week }\end{array}$ \\
\hline Fail to Discover Errors & FDE & $=\mathrm{IF}(\mathrm{TB}>0,(\mathrm{UE}-\mathrm{DE}) / \mathrm{TDCE}, 0)$ & $\begin{array}{l}\text { Tasks/ } \\
\text { week }\end{array}$ \\
\hline $\begin{array}{l}\text { Rework (decision) to Correct } \\
\text { Errors }\end{array}$ & RCE & $=\mathrm{IF}(\mathrm{TB}>0, \mathrm{IF}(\mathrm{SP}>0 \| \mathrm{CP}>0,(1-\mathrm{RESR}) * \mathrm{KE} / \mathrm{SDM}, \mathrm{KE} / \mathrm{SDM}), 0)$ & $\begin{array}{l}\text { Tasks/ } \\
\text { week }\end{array}$ \\
\hline Fail to Correct Errors & FCE & $=\mathrm{IF}(\mathrm{TB}>0,(\mathrm{KE}-\mathrm{RCE}) / \mathrm{TDCE}, 0)$ & $\begin{array}{l}\text { Tasks/ } \\
\text { week }\end{array}$ \\
\hline $\begin{array}{l}\text { Work Rate: performed work in } \\
\text { each week }\end{array}$ & WR & $=\mathrm{WC}-\mathrm{WW}$ & $\begin{array}{l}\text { Tasks/ } \\
\text { week }\end{array}$ \\
\hline Reschedule Inexecutable Work & RIW & $=\mathrm{KIW} / \mathrm{SDM}$ & $\begin{array}{l}\text { Tasks/ } \\
\text { week }\end{array}$ \\
\hline Work Waited/wasted & WW & $=$ FDIW + FRIW & $\begin{array}{l}\text { Tasks/ } \\
\text { week }\end{array}$ \\
\hline Redesign Product Features & RPF & $=\mathrm{IF}(\mathrm{SP}>0,(1-\mathrm{REDR}) *(1-\mathrm{FIR}) * \mathrm{KWPI} / \mathrm{SDM},(1-\mathrm{FIR}) * \mathrm{KWPI} / \mathrm{SDM})$ & $\begin{array}{l}\text { Tasks/ } \\
\text { week }\end{array}$ \\
\hline $\begin{array}{l}\text { Redesign Working Methods to } \\
\text { remove unnecessary works }\end{array}$ & RWM & $=(\mathrm{FIR} * \mathrm{KWPI}) / \mathrm{SDM}$ & $\begin{array}{l}\text { Tasks/ } \\
\text { week }\end{array}$ \\
\hline Increase in Resources & INRES & $=\mathrm{IF}(\mathrm{CP}>0,(1-\mathrm{RESR}) *(\mathrm{CM} * \mathrm{EV}) / \mathrm{SDM},(\mathrm{CM} * \mathrm{EV}) / \mathrm{SDM})$ & $\begin{array}{l}\text { Tasks/ } \\
\text { week }\end{array}$ \\
\hline Cost Rate & $\mathrm{CR}$ & $=\mathrm{IF}(\mathrm{TB}>0,0.09 * \mathrm{NWC}, 0)$ & M€ \\
\hline Benefit Rate & BR & $=\mathrm{IF}(\mathrm{TB}>0,0.125 * \mathrm{WDC}+0.025 * \mathrm{RWF}-0.005 * \mathrm{WCI}+\mathrm{EVII}, 0)$ & $\mathrm{M} €$ \\
\hline Budget Expansion Rate & BER & $=\mathrm{IF}(\mathrm{TB}=0$, delay $(\mathrm{RES} * 0.09, \mathrm{DBE}), 0)$ & M€ \\
\hline $\begin{array}{l}\text { Innovative Opportunities in } \\
\text { Weekly Schedule }\end{array}$ & IOWS & $=\mathrm{FWPI} * \mathrm{PU} * \mathrm{WC}$ & Tasks \\
\hline Known Innovative Solutions & KIS & $=\mathrm{CM}^{*} \mathrm{IOWS}$ & Tasks \\
\hline $\begin{array}{l}\text { Disruptions: project uncertainty } \\
\text { in terms of social, economic, } \\
\text { technical, environmental and } \\
\text { political risks }\end{array}$ & DD & $=\mathrm{PU} *$ Random $\operatorname{Gamma}(0,0.4,1,0,1)$ & Dmnl \\
\hline Changes in Weekly Plan & CWP & $\begin{array}{l}=\mathrm{IF}(\mathrm{WTD}>0, \min (\mathrm{WTD}, \mathrm{WC}) * \min (1, \mathrm{DD}+(1+0.1 * \mathrm{PC}) *((\mathrm{RPF}+\mathrm{RWM}+\mathrm{RCE}) / \\
\mathrm{WC}), 0)\end{array}$ & Tasks \\
\hline Known Inexecutable Work & KIW & $=\mathrm{CM}^{*} \mathrm{CWP}$ & Tasks \\
\hline Indicated Completion Time & ICT & $=$ time ()$+\mathrm{WTD} /(\operatorname{RES} *$ Average $(\mathrm{P}))$ & Weeks \\
\hline Indicated Completion Cost & ICC & $=\mathrm{RC}+\mathrm{RC} /(\mathrm{WC} * \mathrm{WTD})$ & M€ \\
\hline $\begin{array}{l}\text { Schedule Pressure (anticipated } \\
\text { schedule overrun) }\end{array}$ & SP & $=\mathrm{ICT}-\mathrm{SCT}$ & Weeks \\
\hline $\begin{array}{l}\text { Cost Pressure (anticipated cost } \\
\text { overrun) }\end{array}$ & $\mathrm{CP}$ & $=\mathrm{ICC}-\mathrm{ACC}$ & M€ \\
\hline Project Quality & PQ & $=\mathrm{WCC} /(\mathrm{WCC}+\mathrm{WCI}+\mathrm{UE}+\mathrm{KE})$ & Dmnl \\
\hline Realised Value & RV & $=\mathrm{RB} / \mathrm{RC}$ & Dmnl \\
\hline $\begin{array}{l}\text { Effect of schedule pressure on } \\
\text { quality }\end{array}$ & EI & $=$ WITH LOOKUP $^{\mathrm{a}}(\mathrm{SP},(0,0),(1,-0.02),(2,-0.04),(3,-0.06),(4,-0.08),(5,-0.1))$ & Dmnl \\
\hline $\begin{array}{l}\text { Effect of undiscovered error on } \\
\text { quality }\end{array}$ & EII & $\begin{array}{l}=\text { WITH LOOKUP }(\mathrm{UE},(0,0),(10,-0.03),(20,-0.06),(30,-0.09),(40,-0.12),(50,- \\
0.15),(60,-0.2),(70,-0.25),(80,-0.3))\end{array}$ & Dmnl \\
\hline $\begin{array}{l}\text { Effect of schedule pressure on } \\
\text { productivity }\end{array}$ & EIII & $\begin{array}{l}=\text { IF }(\mathrm{PC} \leq 0.4, \text { WITH LOOKUP }(\mathrm{SP},(0,0),(1,0.03),(2,0.066),(3,0.1),(4,0),(5,- \\
0.05)), \text { Else IF }(0.4<\mathrm{PC}<=0.7, \text { WITH LOOKUP (SP, }(0,0),(1,0.05),(2,0.1), \\
(3,0),(4,-0.025),(5,-0.05)), \text { WITH LOOKUP (SP, }(0,0),(1,0.1),(2,0.05),(3,0),(4,- \\
0.025),(5,-0.05)))\end{array}$ & Dmnl \\
\hline $\begin{array}{l}\text { Effect of project team practices } \\
\text { on speed of decision-making }\end{array}$ & EIV & $\begin{array}{l}=\text { WITH LOOKUP }(\mathrm{CMS},(0.01,6),(0.1,5),(0.4,4),(0.6,3),(0.8,2),(0.9,1.5),(0.95 \text {, } \\
1))\end{array}$ & Weeks \\
\hline
\end{tabular}


Engineering Project Organization Journal (September 2021) Volume 10

\begin{tabular}{|l||l|l|l|}
\hline Variables: descriptions & Names & Equations & Units \\
\hline $\begin{array}{l}\text { Effect of schedule pressure on } \\
\text { resource }\end{array}$ & EV & = WITH LOOKUP $(\mathrm{SP},(0,0),(2,3),(4,5),(6,7),(8,9),(10,11))$ & Resources \\
\hline $\begin{array}{l}\text { Effect of capability and } \\
\begin{array}{l}\text { motivation to coordinate work on } \\
\text { productivity }\end{array}\end{array}$ & EVI & $\begin{array}{l}\text { = WITH LOOKUP }(\mathrm{CM},(0,-0.05),(0.2,-0.03),(0.4,-0.01), \\
(0.6,0),(0.8,0.03),(0.95,0.05))\end{array}$ & Dmnl \\
\hline $\begin{array}{l}\text { Effect of completion time on } \\
\text { benefit }\end{array}$ & EVII & $=\mathrm{IF}(\mathrm{WTD}==0$, WITH LOOKUP $(\mathrm{SP},(-4,2),(-2,1),(0,0),(2,-2),(4,-4),(8,-8)), 0)$ & M€ \\
\hline
\end{tabular}

${ }^{a}$ WITH LOOKUP is a table function to specify a nonlinear relationship between a variable and its causes. 